\title{
Anti-diabetic activity of insulin-degrading enzyme inhibitors mediated by multiple hormones
}

\section{Citation}

Maianti, Juan Pablo, Amanda McFedries, Zachariah H. Foda, Ralph E. Kleiner, Xiu Quan Du, Malcolm A. Leissring, Wei-Jen Tang, et al. 2014. Anti-Diabetic Activity of Insulin-Degrading Enzyme Inhibitors Mediated by Multiple Hormones. Nature 511, no. 7507: 94-98. doi:10.1038/ nature13297.

\section{Published Version}

doi:10.1038/nature13297

\section{Permanent link}

http://nrs.harvard.edu/urn-3:HUL.InstRepos:27409185

\section{Terms of Use}

This article was downloaded from Harvard University's DASH repository, and is made available under the terms and conditions applicable to Open Access Policy Articles, as set forth at http:// nrs.harvard.edu/urn-3:HUL.InstRepos:dash.current.terms-of-use\#OAP

\section{Share Your Story}

The Harvard community has made this article openly available.

Please share how this access benefits you. Submit a story.

\section{Accessibility}




\title{
Anti-diabetic activity of insulin-degrading enzyme inhibitors mediated by multiple hormones
}

\author{
Juan Pablo Maianti ${ }^{1}$, Amanda McFedries ${ }^{1}$, Zachariah H. Foda ${ }^{2}$, Ralph E. Kleiner ${ }^{1}$, Xiu Quan \\ Du $^{3}$, Malcolm A. Leissring ${ }^{4}$, Wei-Jen Tang ${ }^{5}$, Maureen J. Charron ${ }^{3}$, Markus A. Seeliger ${ }^{2}$, \\ Alan Saghatelian ${ }^{1}$, and David R. Liu ${ }^{1,6}$ \\ ${ }^{1}$ Department of Chemistry and Chemical Biology, Harvard University, 12 Oxford Street, \\ Cambridge, Massachusetts 02138, USA \\ 2Department of Pharmacological Sciences, Stony Brook University, 1 Circle Road, Stony Brook, \\ New York 11794, USA \\ ${ }^{3}$ Department of Biochemistry, Albert Einstein College of Medicine, 1300 Morris Park Avenue, \\ Bronx, New York 10461, USA \\ ${ }^{4}$ Institute for Memory Impairments and Neurological Disorders, University of California, Irvine, \\ 3204 Biological Sciences III, Irvine, California 92697, USA \\ ${ }^{5}$ Ben-May Department for Cancer Research, University of Chicago, 929 East 57th Street, \\ Chicago, Illinois 60637, USA \\ ${ }^{6}$ Howard Hughes Medical Institute, Department of Chemistry and Chemical Biology, Harvard \\ University, 12 Oxford Street, Cambridge, Massachusetts 02138, USA
}

\section{Abstract}

Despite decades of speculation that inhibiting endogenous insulin degradation might treat type-2 diabetes ${ }^{1,2}$, and the identification of $I D E$ (insulin-degrading enzyme) as a diabetes susceptibility gene $^{3,4}$, the relationship between the activity of the zinc metalloprotein IDE and glucose homeostasis remains unclear. Although $\mathrm{Ide}^{-/-}$mice have elevated insulin levels, they exhibit impaired, rather than improved, glucose tolerance that may arise from compensatory insulin signalling dysfunction ${ }^{5,6}$. IDE inhibitors that are active in vivo are therefore needed to elucidate IDE's physiological roles and to determine its potential to serve as a target for the treatment of

\footnotetext{
(C) Macmillan Publishers Limited. All rights reserved 2014

Correspondence and requests for materials should be addressed to D.R.L. (drliu@fas.harvard.edu) and A.S. (saghatelian@chemistry.harvard.edu).

Online Content Any additional Methods, Extended Data display items and Source Data are available in the online version of the paper; references unique to these sections appear only in the online paper.

Supplementary Information is available in the online version of the paper.

Author Contributions J.P.M., A.M., Z.H.F., R.E.K. and X.Q.D. performed the experiments. M.A.L. provided the Ide ${ }^{-/-}$mice. W.J.T. provided IDE protein for structural studies. M.J.C. supervised the $\mathrm{Gcgr}^{-/}$studies. M.A.S. supervised the IDE• $\mathbf{6 b}$ structural studies. A.S. supervised the pharmacological validation of $\mathbf{6 b K}$ and the in vivo studies. D.R.L. supervised the discovery of IDE inhibitors, the pharmacological studies and the in vivo studies. All authors analysed the data and wrote the manuscript.

Author Information The coordinates and the structure factors of the IDE $\bullet \mathbf{6 b}$ complex have been deposited in the Protein Data Bank under the accession code 4 LTE. The authors declare competing financial interests: details are available in the online version of the paper. Readers are welcome to comment on the online version of the paper.
} 
diabetes. Here we report the discovery of a physiologically active IDE inhibitor identified from a DNA-templated macrocycle library. An X-ray structure of the macrocycle bound to IDE reveals that it engages a binding pocket away from the catalytic site, which explains its remarkable selectivity. Treatment of lean and obese mice with this inhibitor shows that IDE regulates the abundance and signalling of glucagon and amylin, in addition to that of insulin. Under physiological conditions that augment insulin and amylin levels, such as oral glucose administration, acute IDE inhibition leads to substantially improved glucose tolerance and slower gastric emptying. These findings demonstrate the feasibility of modulating IDE activity as a new therapeutic strategy to treat type-2 diabetes and expand our understanding of the roles of IDE in glucose and hormone regulation.

To discover small-molecule modulators of IDE, we performed in vitro selections on a DNAtemplated library of 13,824 synthetic macrocycles ${ }^{7,8}$ for the ability to bind immobilized mouse IDE, resulting in six candidate IDE-binding molecules (Extended Data Fig. 1).The 20-membered macrocycle $6 \mathbf{b}$ (Fig. 1a, half-maximum inhibitory concentration $\mathrm{IC}^{50}=60$ $\mathrm{nM}$ ) potently inhibited IDE activity in three complementary assays (Extended Data Fig. 2) ${ }^{9}$. We synthesized and biochemically assayed 30 analogues of $\mathbf{6 b}$ in which each building block was systematically varied to elucidate the structural and stereochemical requirements (Extended Data Fig. 1), and based on the results we identified the inhibitor $6 \mathbf{b K}\left(\mathrm{IC}_{50}=50\right.$ nM, Fig. 1b) as an ideal candidate for in vivo studies.

The selectivity of $\mathbf{6 b K}$ in vitro was $\geq 1,000$-fold for inhibition of IDE over all other metalloproteases tested, a substantial improvement over the previously reported substrate mimetic hydroxamic acid inhibitor Ii1 ${ }^{10}$ (Fig. 1d, e). The selectivity of $\mathbf{6 b K}$, coupled with its ability to inhibit IDE in a synergistic, rather than competitive, manner with Ii1 (Extended Data Fig. 2), led us to speculate that the macrocycle engages a binding site distinct from the enzyme's catalytic site (Supplementary Discussion).

We determined the X-ray crystal structure of catalytically inactive cysteine-free human $\mathrm{IDE}^{11}$ bound to $\mathbf{6 b}$ at $2.7 \AA$ A resolution (Fig. 1g, Extended Data Fig. 3). Macrocycle $\mathbf{6 b}$ occupies a binding pocket at the interface of IDE domains 1 and 2, and is positioned $11 \AA$ away from the catalytic zinc ion (Fig. 1h). This distal binding site is a unique structural feature of IDE compared to related metalloproteases ${ }^{12}$, and does not overlap with the binding site of Ii1 ${ }^{10}$. IDE mutations predicted by the structure to impede macrocycle binding led to losses of $\mathbf{6 b K}$ potency (Fig. 1f), and complementary changes in $\mathbf{6 b}$ analogues rescued inhibition (Supplementary Discussion, Extended Data Fig. 4). The structure predicts that by engaging this distal site the macrocycle precludes substrate binding and abrogates key interactions that are necessary to unfold peptides for cleavage (Supplementary Video) ${ }^{13}, 14$.

We characterized the stability, and the physicochemical and pharmacokinetic properties, of 6bK formulated in Captisol ${ }^{15}$, a $\beta$-cyclodextrin agent used to improve delivery through intraperitoneal (i.p.) injection at $2 \mathrm{mg}$ 6bK per animal (Supplementary Discussion, Extended Data Fig. 5). The long half-life in mouse plasma (> $2 \mathrm{~h}$ ) and in circulation (>1h) of $\mathbf{6 b K}$ suggested that it was suitable for in vivo studies (Extended Data Fig. 5). Injection of $\mathbf{6 b K}$ resulted in high levels of the inhibitor $\left(>100\right.$-fold $\left.\mathrm{IC}_{50}\right)$ in peripheral circulation and in the 
liver and kidneys, the main insulin-degrading organs. In contrast, $\mathbf{6 b K}$ was undetectable in brain tissue, where IDE is known to degrade amyloid peptides ${ }^{5}$ (Extended Data Fig. 5), and levels of $A \beta(40)$ and $A \beta(42)$ peptides in mice injected with $6 \mathbf{b K}$ were unchanged (Extended Data Fig. 5). Taken together, these findings suggested the viability of $6 \mathbf{b K}$ as an in vivo IDE inhibitor.

To evaluate the ability of $\mathbf{6 b K}$ to inhibit IDE activity in vivo, we subjected non-fasted mice to insulin tolerance tests $30 \mathrm{~min}$ after a single injection with $\mathbf{6 b K}$ ( $2 \mathrm{mg}$ per animal, $80 \mathrm{mg}$ $\left.\mathrm{kg}^{-1}\right)$. Mice treated with $\mathbf{6 b K}$ experienced lower hypoglycaemia and higher insulin levels compared to vehicle controls $(P<0.01$, see below and Extended Data Fig. 5). These experiments establish that a selective and physiologically stable pharmacological IDE inhibitor can augment the abundance and activity of insulin in vivo.

Next we determined the physiological consequences of acute IDE inhibition for glucose tolerance. We used two methods of glucose delivery (oral gavage or i.p. injection ${ }^{16}$ ) and two different mouse models (lean or diet-induced obese (DIO) mice ${ }^{17,18}$ ). These four conditions were chosen to survey the role of IDE activity under a broad range of endogenous insulin levels and insulin sensitivities ${ }^{16,17}$. Oral glucose administration results in greater insulin secretion compared to injected glucose delivery (Extended Data Fig. 6) that arises from the 'incretin effect' ${ }^{\prime}$ ', 19 . DIO mice display hyperinsulinaemia and insulin resistance, and serve as a model for early type- 2 diabetes in humans ${ }^{18}$.

During oral glucose tolerance tests (OGTTs, Fig. 2a and b), both lean and DIO mice treated with $\mathbf{6 b K}$ displayed significantly improved glucose tolerance compared to control groups treated either with vehicle alone, or with the inactive stereoisomer bisepi-6bK (Figs 1c, 2a and b; Extended Data Fig. 7). Effects of similar magnitude on oral glucose tolerance in mice have been observed from several human diabetes therapeutics (Extended Data Fig. 8) ${ }^{19-21}$. The vehicle and bisepi-6bK control groups exhibited similar blood glucose profiles, indicating that that the effects of $\mathbf{6 b K}$ on glucose tolerance are lost when the stereochemistry of $\mathbf{6 b K}$ is altered in a way that abolishes IDE inhibition. Collectively, these observations represent the first demonstration that transient IDE inhibition improves blood glucose tolerance $^{1}$.

We repeated the above experiments with $\mathbf{6 b K}$ using i.p.-injected glucose tolerance tests (IPGTTs). In contrast to the observed improvement in oral glucose tolerance on $\mathbf{6 b K}$ treatment, IDE inhibition with $\mathbf{6} \mathbf{b K}$ followed by a glucose injection $\left(1.5 \mathrm{~g} \mathrm{~kg}^{-1}\right.$ i.p. $)$ surprisingly resulted in impaired glucose tolerance in both lean and obese mice compared to vehicle alone or bisepi-6bK-treated controls (Fig. $2 \mathrm{~d}$ and e). DIO mice treated with $\mathbf{6 b K}$ followed by glucose injection displayed a biphasic response: glucose levels were lower over the initial $30 \mathrm{~min}$ of the IPGTT, followed by a hyperglycaemic 'rebound' starting $1 \mathrm{~h}$ after glucose injection (Fig. 2e and Extended Data Fig. 7).To further test if the effects of $\mathbf{6 b K}$ are specific to its interaction with IDE, we repeated these experiments using Ide $e^{-/-}$knockout mice ${ }^{5,6}$. Mice lacking IDE were not affected by $\mathbf{6 b K}$ treatment and exhibited OGTT and IPGTT blood glucose responses comparable to that of vehicle-treated cohorts (Fig. $2 \mathrm{c}$ and f), suggesting that blood glucose profile improvement during OGTT and impairment during IPGTT of 6bK-treated wild-type mice are mediated by IDE. 
The dependence of the physiological response to $\mathbf{6 b K}$ on the route of glucose administration cannot be easily explained by a simple model in which IDE only degrades insulin. Instead, these results strongly suggest a role for IDE in modulating other glucose-regulating hormones in vivo beyond insulin. The biochemical properties of IDE and its substrate recognition mechanism ${ }^{12,13}$ enable this enzyme to cleave a wide range of peptide substrates in vitro for which experimental validation in vivo has not been previously possible (Supplementary Table 1). Two glucose-regulating hormones, beyond insulin, that are potential candidates for physiological regulation by IDE are glucagon and amylin. Whereas purified IDE can cleave these two peptides in vitro ${ }^{22,23}$, neither hormone is known to be regulated by IDE in vivo or ex vivo.

To probe the possibility that glucagon and/or amylin are regulated in vivo by IDE, we measured plasma levels of these hormones in DIO mice treated with $\mathbf{6 b K}$ or vehicle alone following IPGTTs (Fig. 3a), and observed substantially higher levels of insulin, glucagon and amylin. Next we injected each of these three putative substrates 30 min after treatment with $\mathbf{6 b K}$ or vehicle alone (Fig. 3b-d).The $\mathbf{6 b K}$-treated cohorts exhibited significantly stronger blood glucose responses to each of these hormones; mice treated with $\mathbf{6 b K}$ experienced hypoglycaemia during insulin tolerance tests (Fig. 3b) and hyperglycaemia following challenges with either amylin ${ }^{24}$ (Fig. 3c) or glucagon (Fig. 3d) compared to control animals (via non-physiological activation of the Cori cycle, and gluconeogenesis, respectively $)^{24-26}$. Moreover, in each case the plasma level of the hormone injected remained elevated at the end of the procedure in $\mathbf{6 b K}$-treated mice relative to control animals (Figs $3 b-d$ insets). Collectively these results reveal that IDE regulates the abundance and physiological effects of glucagon and amylin, in addition to insulin.

Amylin is co-secreted with insulin, and is involved in glycaemic control by inhibiting gastric emptying, promoting satiety and antagonizing glucagon secretion ${ }^{24}$, 25. Pramlintide (Symlin) is a synthetic amylin derivative used clinically to control post-prandial glucose levels ${ }^{20,21}$. To determine the effects of IDE inhibition on endogenous amylin signalling, we measured gastric emptying efficiency, an amylin-mediated process ${ }^{25}$. Mice treated with $\mathbf{6 b K}$ exhibited twofold slower gastric emptying compared to vehicle and bisepi-6bK-treated controls (Fig. 3e). Importantly, co-administration of AC187, a 25-mer peptide amylin receptor antagonist ${ }^{25}$, blocked the effects of $\mathbf{6 b K}$ on gastric emptying (Fig. 3e). Collectively, these data reveal that IDE inhibition can slow post-prandial gastric emptying by modulating amylin signalling in vivo at physiologically relevant levels. Amylin-mediated effects on gastric emptying and satiety have been recognized to have therapeutic relevance 20,21 , and our results demonstrate a small-molecule-based strategy to modulate amylin signalling (Extended Data Fig. 10).

Higher glucagon levels on $\mathbf{6 b K}$ treatment provide a possible explanation for impaired glucose tolerance during IPGTT experiments. Substrates are processed by IDE at rates dependent on their relative concentrations (Supplementary Discussion). We observed twoto four-fold higher insulin levels during OGTTs than IPGTTs, consistent with the incretin effect $^{16-19}$ (Extended Data Fig. 6). During an OGTT, IDE inhibition therefore results primarily in an increase in insulin signalling and lower blood glucose levels. In contrast, during an IPGTT, insulin secretion levels are lower ${ }^{16-19}$, IDE processes proportionally more 
glucagon, and the loss of IDE activity thus results in higher glucagon and glucose levels (Figs 2d, e and 3a; Supplementary Discussion) ${ }^{16-19}$.

To test this hypothesis, we repeated the glucose tolerance experiments using $\mathrm{Gcgr}^{-/-}$mice that lack the G-protein-coupled glucagon receptor (Fig. $3 \mathrm{f}$ and g) ${ }^{26}$. Treatment of $\mathrm{Gcgr}^{-/-}$ mice with $\mathbf{6 b K}$ followed by an OGTT resulted in improved glucose tolerance as expected (Fig. 3f), consistent with a model in which insulin signalling in these mice is intact and regulated by IDE. In contrast, glucose tolerance in $\mathrm{Gc} \mathrm{gr}^{-1-}$ mice following IPGTT was not impaired by $\mathbf{6 b K}$ treatment, consistent with a model in which glucagon signalling is responsible for driving higher glucose levels in wild-type mice on IDE inhibition during IPGTTs (compare Figs $3 \mathrm{~g}$ and 2d). In addition, $6 \mathbf{b K}$ treatment augmented the expression of liver gluconeogenic markers regulated by endogenous glucagon signalling following a pyruvate injection (Supplementary Discussion, Extended Data Fig. 9). These results collectively show that the ability of IDE to regulate glucagon in vivo can account for the impaired glucose tolerance observed during IPGTTs (see the Supplementary Discussion on the hyperglycaemic rebound phase in DIO mice).

The discovery and application of the physiologically active IDE inhibitor $\mathbf{6 b K}$ reveals that transient IDE inhibition can improve glucose tolerance under conditions that mimic the intake of a meal. In the context of recent genetics studies identifying $I D E$ as a diabetes susceptibility gene ${ }^{3,4}$, our findings establish the potential of IDE as a target for the treatment of diabetes ${ }^{1,2}$. Our study also reveals a new requirement for therapeutic strategies that target IDE-namely, that transient IDE inhibition during meals, rather than chronic treatment, is desirable to minimize elevation of glucagon signalling (Extended Data Fig. $10)^{21,27}$. Plausible pharmacological strategies to circumvent elevation of postprandial glucagon levels include: (1) development of fast- and short-acting pre-meal IDE inhibitors ${ }^{21}$; (2) combination therapy of an IDE inhibitor with glucagon-lowering incretin therapies $^{20,21}$; and (3) co-administration with glucagon receptor antagonists ${ }^{27}$. Moreover, existing anti-diabetic therapeutics when co-administered with an IDE inhibitor may result in synergistic effects ${ }^{28}$; indeed $\mathbf{6 b K}$ treatment results in stronger improvement in oral glucose tolerance when co-administered with the DPP4 inhibitor sitagliptin (Extended Data Fig. $8)^{19,20}$. In addition, the IDE $\bullet \mathbf{6} \mathbf{b}$ structure raises the possibility of developing IDE inhibitors that selectively impede insulin degradation without affecting glucagon degradation. These findings collectively inform and motivate additional studies to progress these discoveries towards new diabetes therapeutics.

\section{METHODS SUMMARY}

The in vitro selection of the DNA-templated library ${ }^{8}$ used $20 \mu$ His $_{6}$-tagged mouse IDE immobilized on cobalt magnetic beads (Invitrogen). IDE inhibition was assayed using the fluorogenic peptide Mca-RPPGFSAFK(Dnp)-OH (R\&D), confirmed using an anti-insulin antibody time-resolved FRET assay (Cysbio), and a LCMS assay for CGRP cleavage fragments in plasma ${ }^{9}$. Macrocyclic inhibitors were synthesized by Fmoc-based solid-phase synthesis and purified by HPLC. LCMS quantitation of $\mathbf{6 b K}$ in biological samples was performed using $\mathbf{6 b K}$ synthesized with ${ }^{13} \mathrm{C}_{6},{ }^{15} \mathrm{~N}_{2}$ lysine (Sigma-Aldrich). 
Wild-type lean and DIO C57BL/6J age-matched male mice (Jackson Laboratories) were used at 14-16, and 24-26 weeks respectively (> 20 weeks of high-fat diet). $\mathrm{Ggr}^{-/-}$and $I d e^{-/-}$mice were fully backcrossed to the C57BL/6J line, bred from heterozygous mice, and used between 11 and 21 weeks. Animals were fasted overnight $14 \mathrm{~h}$ for all experiments, except for the insulin tolerance test, which required $5 \mathrm{~h}$ of fasting during the morning. Blood glucose was measured from tail nicks using AccuCheck (Aviva) meters. Trunk blood was obtained for plasma hormone measurements using the Multiplexed Mouse Metabolic Hormone panel (Milliplex, EMD Millipore) on a Luminex FlexMap 3D instrument. 


\section{Extended Data}

a

IDE in vitro selection 1 results

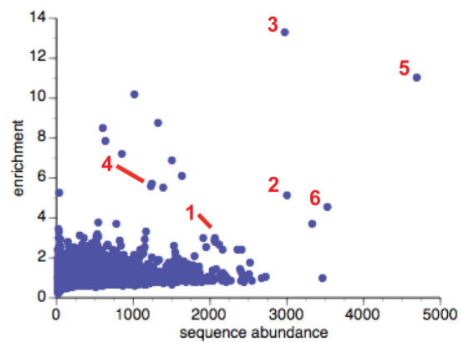

IDE in vitro selection 2 results

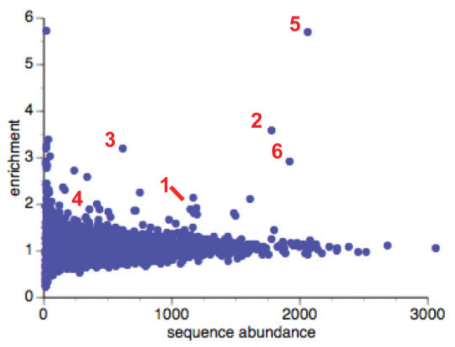

b

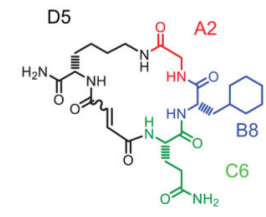

1a (cis olefin) $\quad \mathrm{IC}_{50}>100 \mu \mathrm{M} \quad$ 2a (cis olefin) $\quad \mathrm{IC}_{50}=10 \mu \mathrm{M}$
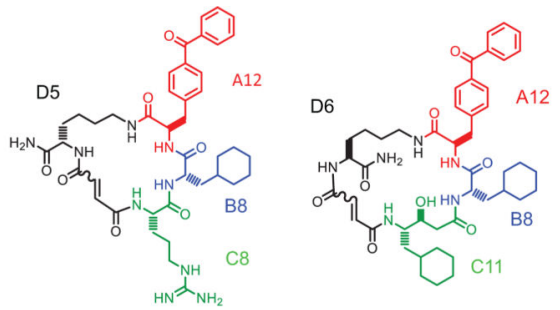

1b (trans olefin) $\quad I_{50}=5.0 \mu \mathrm{M} \quad 2 \mathbf{b}$ (trans olefin) $\quad \mathrm{IC}_{50}=0.14 \mu \mathrm{M} \quad 3 \mathbf{b}$ (trans olefin) $I \mathrm{C}_{50}=1.5 \mu \mathrm{M}$
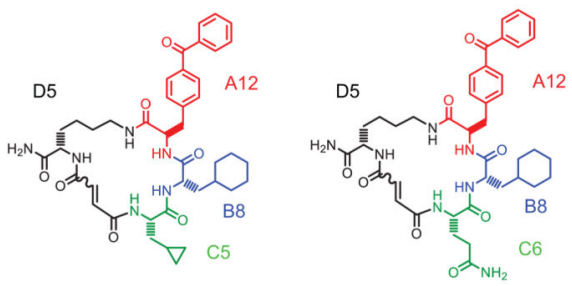

4a (cis olefin) $\quad I C_{50}>100 \mu \mathrm{M} \quad 5 \mathrm{a}$ (cis olefin) $\quad \mathrm{IC}_{50}>20 \mu \mathrm{M}$

$4 \mathrm{~b}$ (trans olefin) $\quad \mathrm{IC}_{50}>100 \mu \mathrm{M} \quad 5 \mathrm{~b}$ (trans olefin) $\mathrm{IC}_{50}=1.0 \mu \mathrm{M}$
$6 \mathbf{a}$ (cis olefin) $\quad \mathrm{IC}_{50}=5.6 \mu \mathrm{M}$

6b (trans olefin) $\quad I_{50}=0.06 \mu \mathrm{M}$

\section{C}
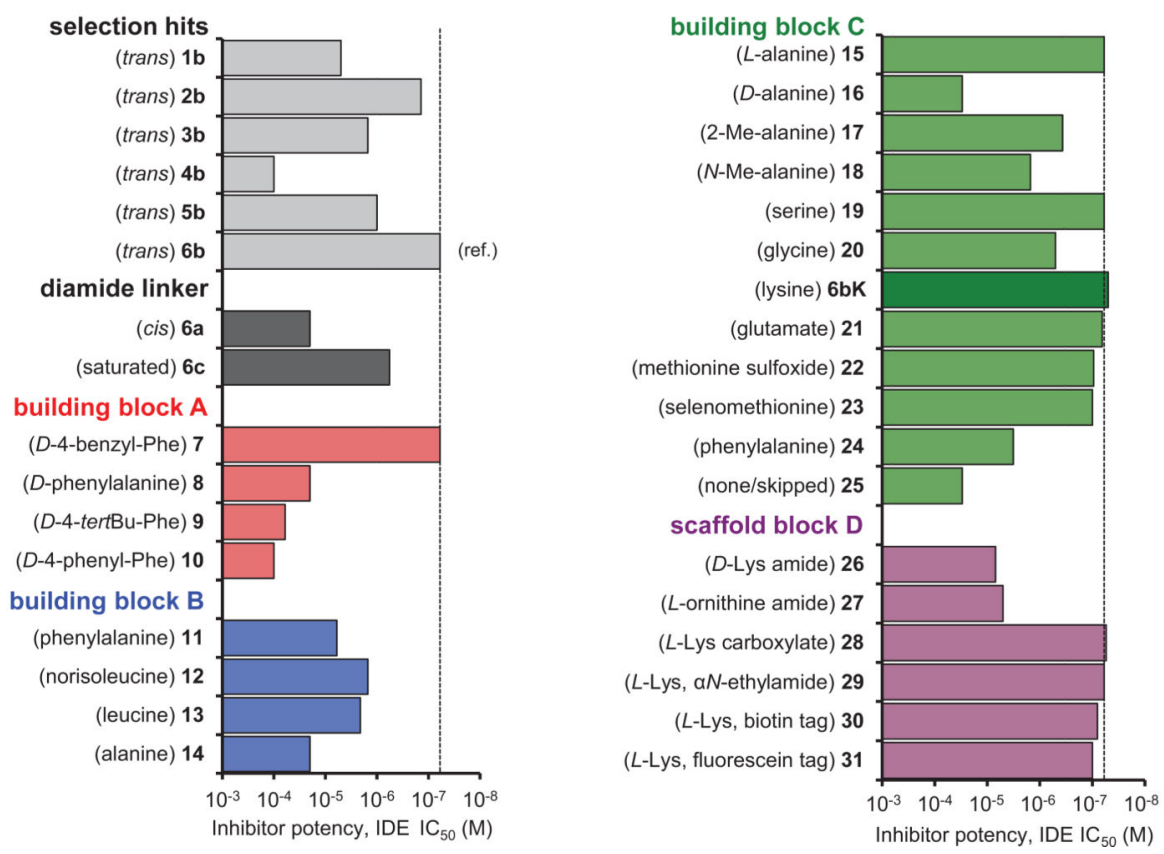

Extended Data Figure 1.

a, Enrichment plots from two independent in vitro selections against N-His ${ }_{6}$-mIDE using a 13,824-membered DNA-templated macrocycle library ${ }^{7,8}$. The numbers highlight compounds enriched at least twofold in both selections. $\mathbf{b}$, Structures of IDE-binding macrocycles 1-6 decoded from DNA library barcodes corresponding to building blocks A, $\mathrm{B}, \mathrm{C}$ and $\mathrm{D}$ (Fig. 1). The cis and trans isomers are indicated by suffices $\mathrm{a}$ and $\mathrm{b}$ respectively 
(for example, $\mathbf{1 a}$ and $\mathbf{1 b}$ ). The two isomers were synthesized as previously reported ${ }^{18,19}$ and separated by HPLC. c, IDE inhibition potency of trans hits $\mathbf{1 b}$ to $\mathbf{6} \mathbf{b}$ compared to 30 structurally related $\mathbf{6 b}$ analogues in which the linker, scaffold and the three building blocks were systematically varied. IDE inhibition activity was assayed by following cleavage of the fluorogenic peptide substrate Mca-RPPGFSAFK(Dnp)-OH.

a Fluorogenic peptide degradation (6b inhibition)

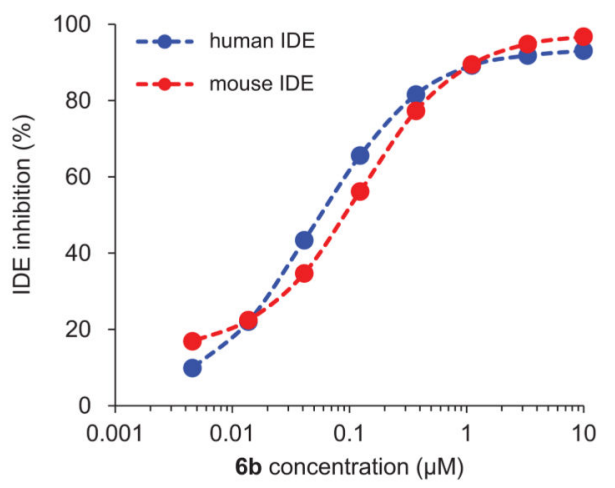

C Insulin degradation (in vitro, HTRF assay)

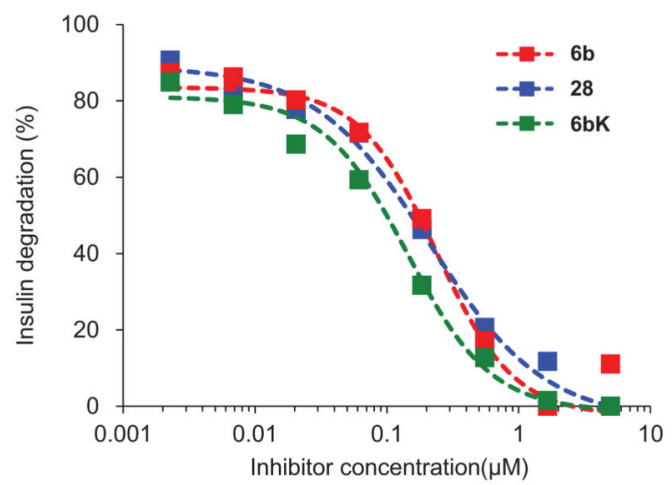

e

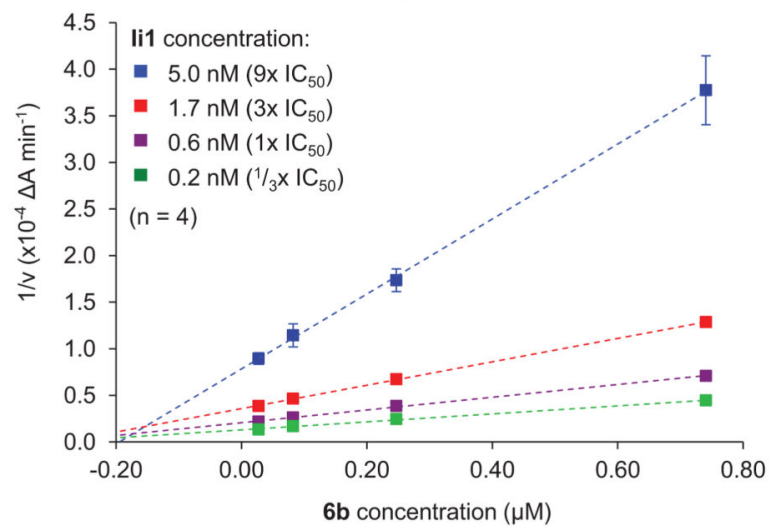

b Fluorogenic peptide degradation (6bK inhibition)

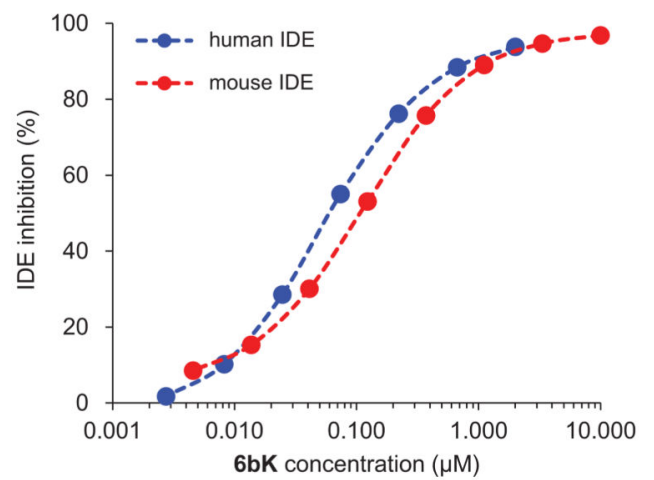

d CGRP cleavage (ex vivo plasma, LCMS assay)

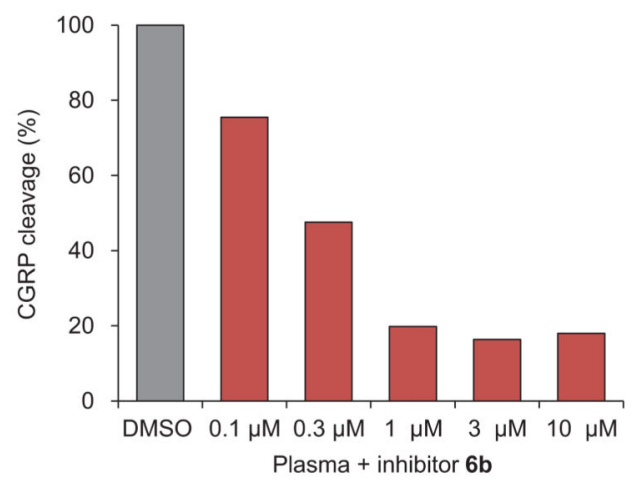

f Double inhibitor plot for $\mathbf{6 b}$ and bacitracin

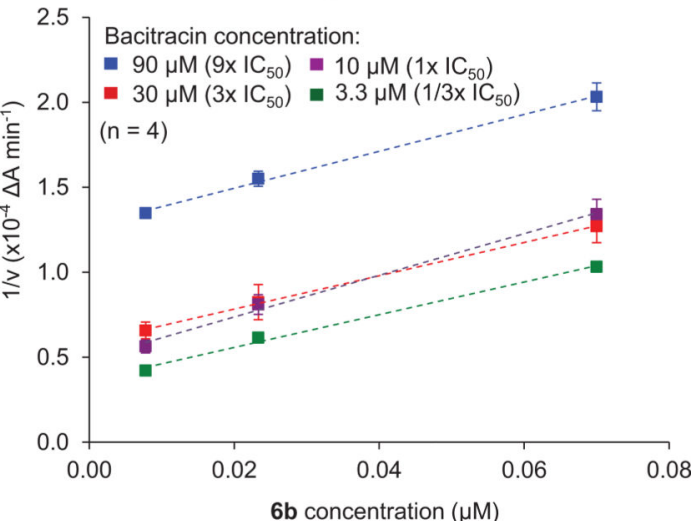

Extended Data Figure 2. Inhibition of human and mouse IDE activity in multiple assays 
a, b, Human IDE shares $95 \%$ sequence homology with mouse IDE $^{13}$, and cleavage of the fluorogenic substrate peptide Mca-RPPGFSAFK(Dnp)-OH by human and mouse IDE is inhibited with similar potency by $\mathbf{6 b}(\mathbf{a})$ and $\mathbf{6 b K}(\mathbf{b})$. c, Homogeneous time-resolved fluorescence (HTRF) assay measuring degradation of insulin by IDE in the presence of $\mathbf{6 b}$, 6bK and analogue 28 (Extended Data Fig. 1). d, LC-MS assay for ex vivo degradation of CGRP $(10 \mu \mathrm{M})$ by endogenous IDE in mouse plasma in the presence of $\mathbf{6 b} . \mathbf{e}, \mathbf{f}$, Biochemical assays suggesting that $\mathbf{6 b}$ binds a site in IDE distinct from the conventional peptide substrate binding site known to bind substrate mimetic Ii1. Yonetani-Theorell double inhibitor plots of IDE activity in the presence of $\mathbf{6 b}$ and Ii1 (panel e), or $\mathbf{6 b}$ and bacitracin (panel f). Crossing lines indicate synergistic and independent binding of inhibitors, while parallel lines indicate competition for binding to the enzyme. 
a

\begin{tabular}{|c|c|}
\hline Data collection & hIDE-CF•6b \\
\hline Space group & $\mathrm{P} 6_{5}$ \\
\hline \multicolumn{2}{|l|}{ Cell dimensions } \\
\hline$a, b, c(\AA)$ & $261.97,261.97,90.8$ \\
\hline$\alpha, \beta, \gamma\left(\left(^{\circ}\right)\right.$ & $90,90,120$ \\
\hline Resolution (A) & $130.99-2.70$ \\
\hline$R_{\text {merge }}$ & $0.135(0.683)$ \\
\hline$I / \sigma I$ & $14.85(2.1)$ \\
\hline Completeness (\%) & $100(99.9)$ \\
\hline Redundancy & 7.4 \\
\hline \multicolumn{2}{|l|}{ Refinement } \\
\hline Resolution (A) & 2.705 \\
\hline No. reflections & 97302 \\
\hline$R_{\text {work }} / R_{\text {free }}$ & $0.1563 / 0.2009$ \\
\hline \multicolumn{2}{|l|}{ No. atoms } \\
\hline Protein & 15531 \\
\hline Ligand/ion & 160 \\
\hline Water & 563 \\
\hline \multicolumn{2}{|l|}{$B$-factors } \\
\hline Protein & $\begin{array}{l}\text { Chain A: } 29.23 \\
\text { Chain B: } 30.51\end{array}$ \\
\hline Ligand/ion & $\begin{array}{l}\text { Chain A: } 64.42 \\
\text { Chain B: } 63.53\end{array}$ \\
\hline Water & 31.67 \\
\hline \multicolumn{2}{|l|}{ R.m.s. deviations } \\
\hline Bond lengths $(\AA)$ & 0.012 \\
\hline Bond angles $\left({ }^{\circ}\right)$ & 1.36 \\
\hline PDB accession code & 4LTE \\
\hline
\end{tabular}

e

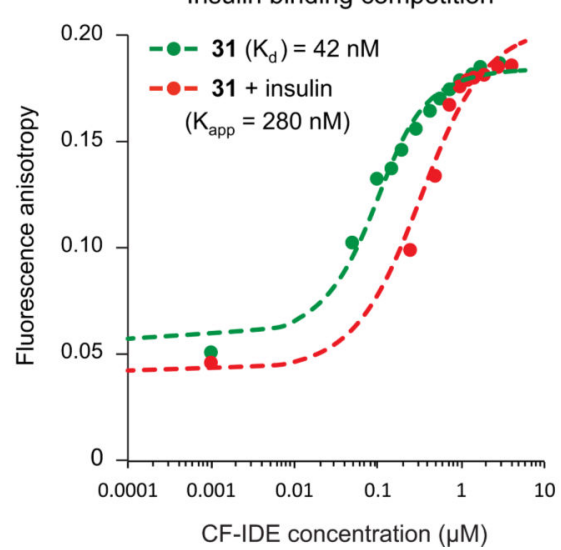

b
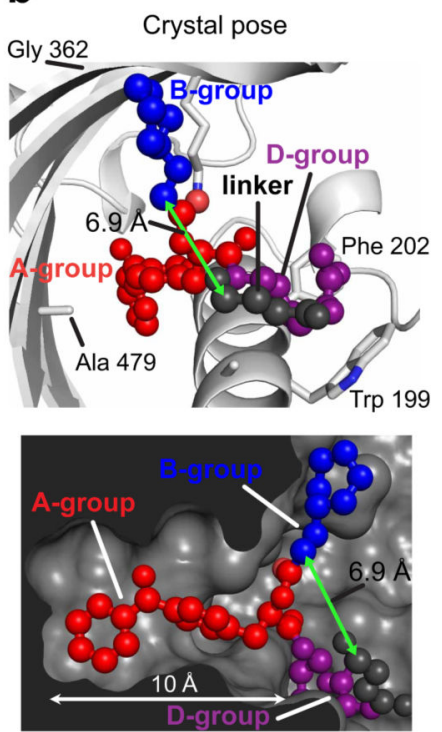

C
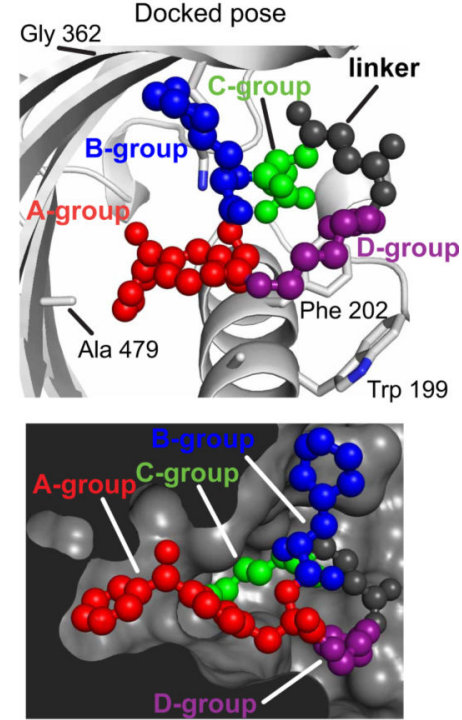

d

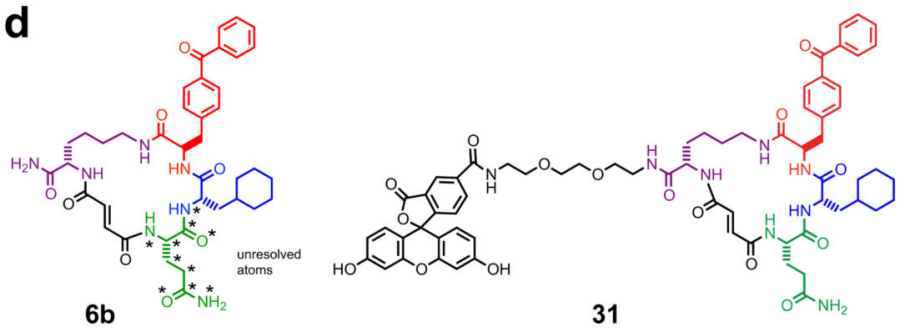

f

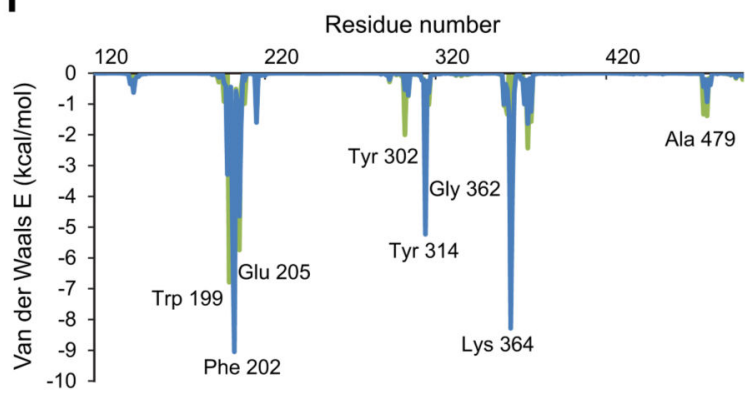

Extended Data Figure 3. Data collection and refinement statistics (molecular replacement), docking simulation for $\mathbf{6 b}$, and competition test between insulin and fluorescein-labelled macrocycle 31 for binding cysteine-free IDE (CF-IDE)

a, One crystal was used to solve the CF-IDE• $\mathbf{6 b}$ structure. The highest-resolution shell is shown in parentheses. Structure coordinates are deposited in the Protein Data Bank (accession number 4 LTE). b, Molecular docking simulations are consistent with the placement of building blocks A and B in the structural model (two views shown: top and bottom panels). The structure of $\mathbf{6 b}$ in the binding site from crystallographic data with composite omit map contoured at $1.0 \sigma$ ( $p$-benzoyl-phenylalanine is shown in red, the 
cyclohexylalanine in blue, the fumarate linker in grey, and the ${ }_{\mathrm{D}}$-lysine backbone in purple). c, Highest-scoring pose from DOCK simulations (glutamine group is shown in green, see Supplementary Information for docking calculations). d, Structure of macrocycle $\mathbf{6 b}$ and fluorescent analogue 31. Stars indicate atoms not resolved in the crystal structure (the Gln building block and four atoms of the flexible macrocycle backbone). e, Competition test between the fluorescein-labelled macrocycle $\mathbf{3 1}$ and insulin for binding CF-IDE. Cysteinefree catalytically inactive IDE was titrated against $0.9 \mathrm{nM}$ macrocycle $\mathbf{3 1}$ alone (filled green circles) or together with $2.15 \mu \mathrm{M}$ insulin (red filled circles), producing a shift in apparent dissociation constant for macrocycle $\mathbf{3 1}$ according to equation (1) (Supplementary Information). f, Residue-decomposed energy of the crystal (green) and docked (blue) poses of $\mathbf{6 b}$ (see Supplementary Information for docking calculations). 
a

6b inhibits A479L mutant poorly versus wild-type IDE

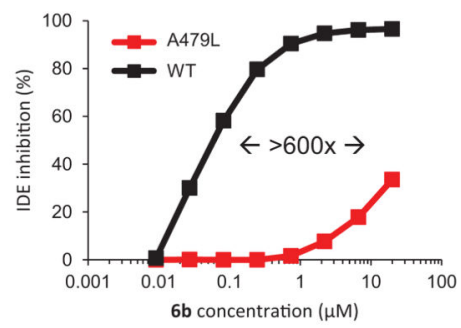

C

6b inhibits $\mathrm{G} 362 \mathrm{Q}$ mutant poorly versus wild-type IDE

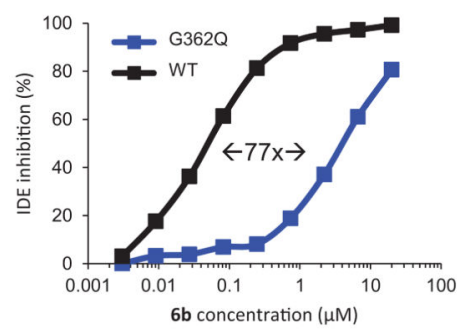

b
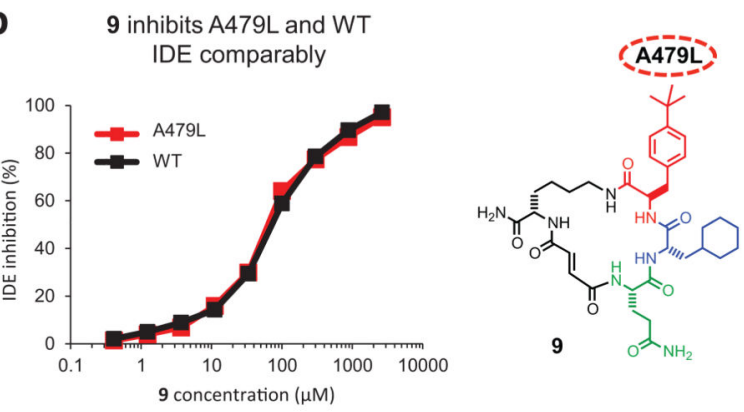

d 13 inhibits G362Q and WT IDE comparably
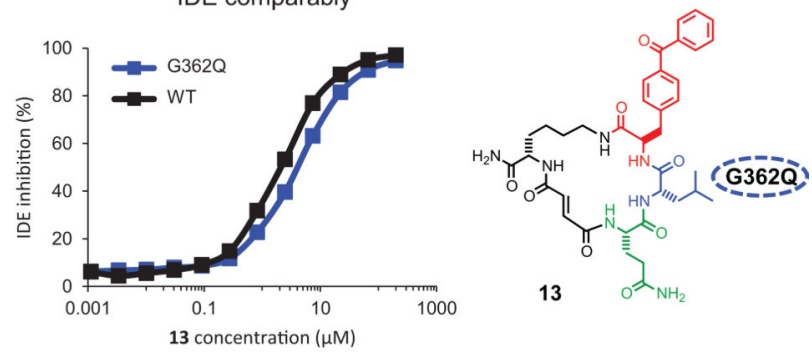

e
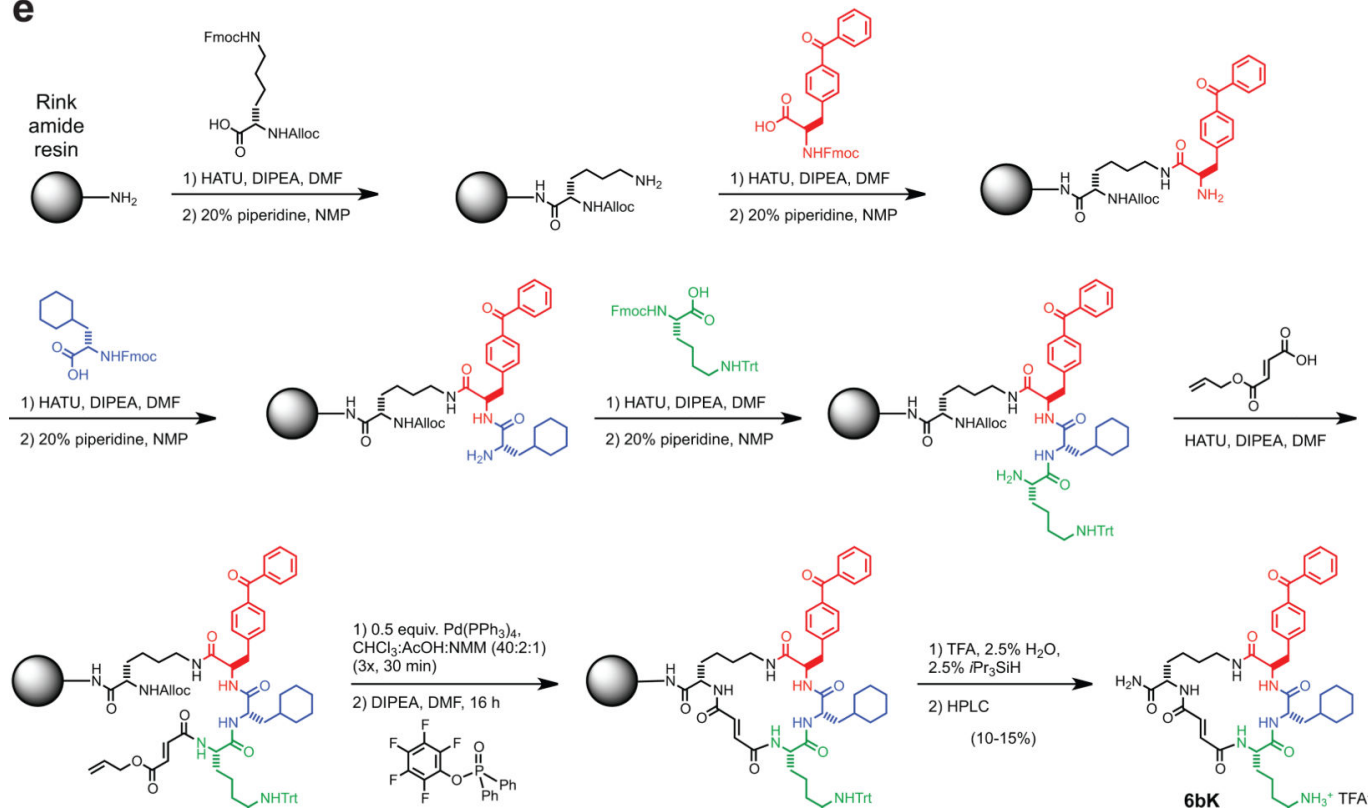

Extended Data Figure 4. Small-molecule/enzyme mutant complementation study to confirm the macrocycle binding site and placement of the benzophenone and cyclohexyl building-block groups

a, IDE mutant A479L is inhibited by $\mathbf{6 b}>600$-fold less potently compared to wild-type IDE. b, Analogue 9, in which the $p$-benzoyl ring is substituted for a smaller $t$-butyl group, inhibits A479L IDE and WT IDE comparably. c, Similarly, IDE mutant G362Q is inhibited 77-fold less potently by $\mathbf{6 b}$ compared with WTIDE. $\mathbf{d}$, Analogue $\mathbf{1 3}$, in which the Lcyclohexyl alanine side chain was substituted with a smaller L-leucine side chain, inhibits G362Q IDE and WT IDE comparably. The full list of IDE mutants investigated is shown in 
Supplementary Table 5. e, Synthetic scheme for $\mathbf{6 b K}$, also used for synthesis of $\mathbf{6 b K}$ analogues.

a

6bK stability ex vivo

\begin{tabular}{lcc}
\hline Sample & mouse & human \\
\hline $\begin{array}{l}\text { Plasma } \\
\text { binding }\end{array}$ & $94 \%$ & $86 \%$ \\
$\begin{array}{l}\text { Plasma } \\
\text { stability }(1 \mathrm{~h})\end{array}$ & $74 \%$ & $83 \%$ \\
$\begin{array}{l}\text { Microsomal } \\
\text { stability }(1 \mathrm{~h})\end{array}$ & $78 \%$ & $80 \%$ \\
\end{tabular}

b

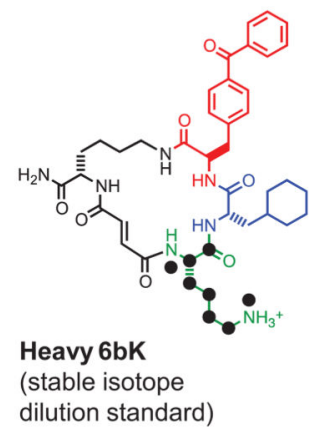

dilution standard)
C 6 bK injection is well tolerated

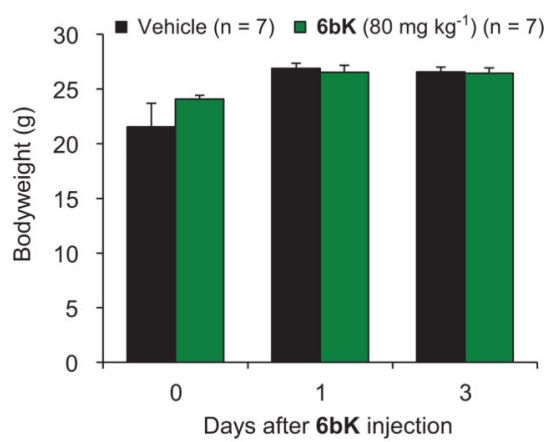

e 6bK levels 150 min. post-injection

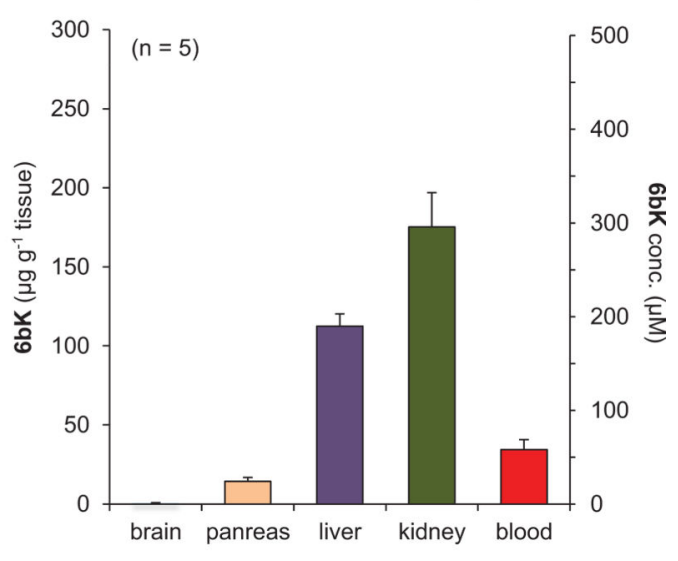

g $6 \mathrm{bK}$ augments insulin action in vivo

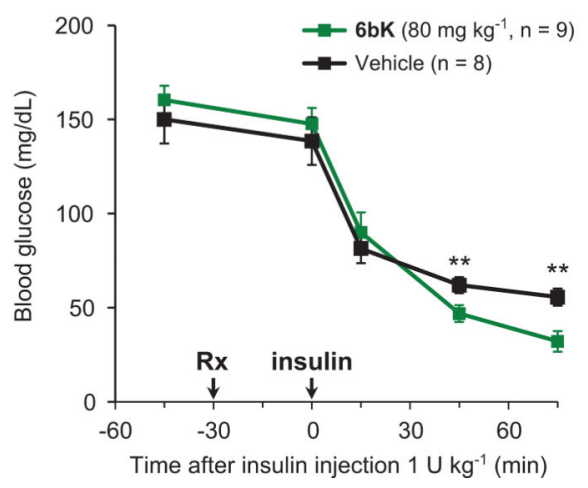

Extended Data Figure 5. Pharmacokinetic parameters of $6 \mathrm{bK}$, augmented insulin hypoglycaemic action by $6 \mathrm{bK}$ in mice, and effects of $6 \mathrm{bK}$ on amyloid peptide levels

a, Plasma binding, plasma stability, and microsomal stability ( $1 \mathrm{~h}$ incubation) data (S. Johnston and C. Mosher, personal communication). b, Heavy-labelled $\mathbf{6 b K}$ was synthesized with ${ }^{15} \mathrm{~N},{ }^{13} \mathrm{C}$-lysine for stable-isotope dilution LC-MS quantitation. $\mathbf{c}$, Behaviour and postexperiment body weight measurements were not affected for mice treated with $\mathbf{6 b K}$ (green; 
$80 \mathrm{mg} \mathrm{kg}^{-1}$ ) versus vehicle alone (black). The mice were active, and displayed normal posture, normal grooming and normal response to stimulation. $\mathbf{d}$, Concentration of $\mathbf{6 b K}$ in mice tissues and plasma collected over $4 \mathrm{~h}$ determined by isotope dilution mass spectrometry (IDMS) with heavy-labelled analogue ( $n=2$ for all data except the last two time-points, for which $n=1$ ). e, Average biodistribution of $6 \mathbf{b K}$ in five lean mice at $150 \mathrm{~min}$ post-injection of $\mathbf{6 b K} 80 \mathrm{mg} \mathrm{kg}^{-1}$ i.p. at the endpoint of an IPGTT experiment. We did not detect $\mathbf{6 b K}$ in the brain even using tenfold concentrated samples for LC-MS injection compared to other tissues. f. Treatment of C57BL/6J lean mice with $6 \mathbf{b K}$ (green, $80 \mathrm{mg}$ $\mathrm{kg}^{-1}, n=6$ ) does not change brain levels of $\mathrm{A} \beta(40)$ or $\mathrm{A} \beta(42)$ peptides in the brain $2 \mathrm{~h}$ post injection compared to treatment with vehicle alone (black, $n=5$ ) or inactive diastereomer bisepi-6bK (brown, $80 \mathrm{mg} \mathrm{kg}^{-1}, n=6$ ). $\mathbf{g}$, Mice treated with a single injection of $\mathbf{6 b K}$ (green, $80 \mathrm{mg} \mathrm{kg}^{-1}$ i.p.) display increased hypoglycaemic response to insulin injection (Humulin-R, $1.0 \mathrm{U} \mathrm{kg}^{-1}$ i.p., see also Fig. 3b). Data shown in $\mathbf{c}-\mathbf{e}$ and $\mathbf{g}$ are representative of two or more independent studies.

C

Unchanged basal blood glucose and basal hormone levels after $6 \mathrm{bK}$ injection alone

Glucose

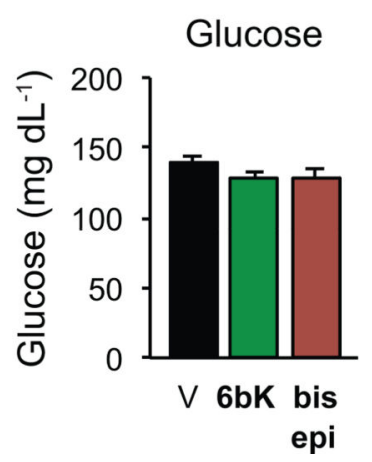

a

Insulin response, 20 min post-glucose

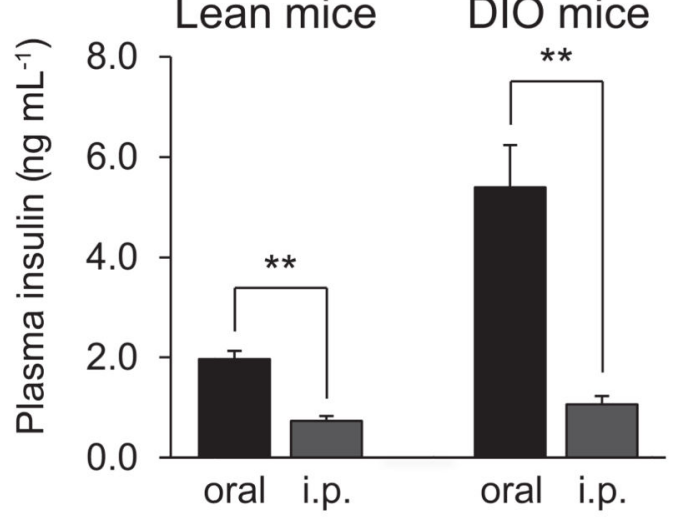

Glucose administration route b Glucagon response, 135 min post-glucose

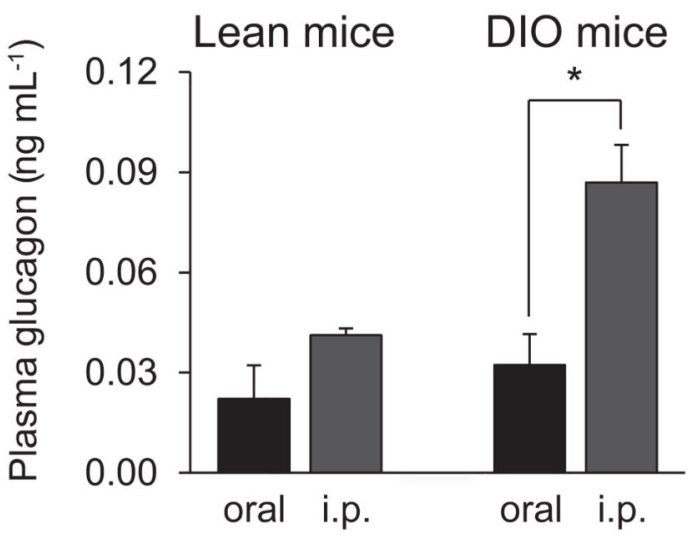

Glucose administration route

\section{C}
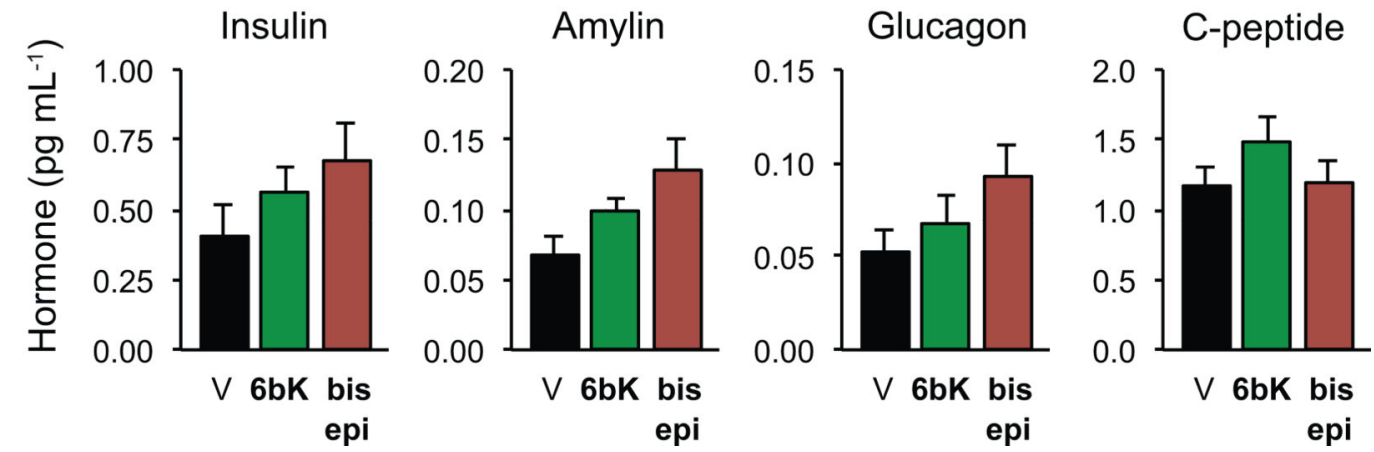
Extended Data Figure 6. Dependence of insulin and glucagon secretion on the route of glucose administration (oral or i.p.) due to both the 'incretin effect' and the hyperinsulinaemic phenotype of DIO versus lean mice

a, The early insulin response to glucose in lean and DIO mice is higher during OGTT than IPGTT. b, Suppression of glucagon secretion post-glucose administration is less effective after IPGTT and in DIO mice. c, Administration of $\mathbf{6 b K}$ (green, $80 \mathrm{mg} \mathrm{kg}^{-1}, n=7$ ) to lean mice not followed by injection of a nutrient such as glucose or pyruvate (see Figs 2-3) did not significantly alter basal blood glucose or basal hormone levels compared to bisepi-6bK (brown, $n=7$ ) or vehicle controls (black, $n=7$ ) $30 \mathrm{~min}$ post-injection. All data points and error bars represent mean \pm s.e.m. Statistics were performed using a two-tail Student's $t$-test, and significance levels shown in the figures are $* P<0.05$ or $* * P<0.01$ between the labelled groups. Data shown are representative of two or more independent studies. 
a Low potency $6 \mathrm{bK}$ diastereomer controls

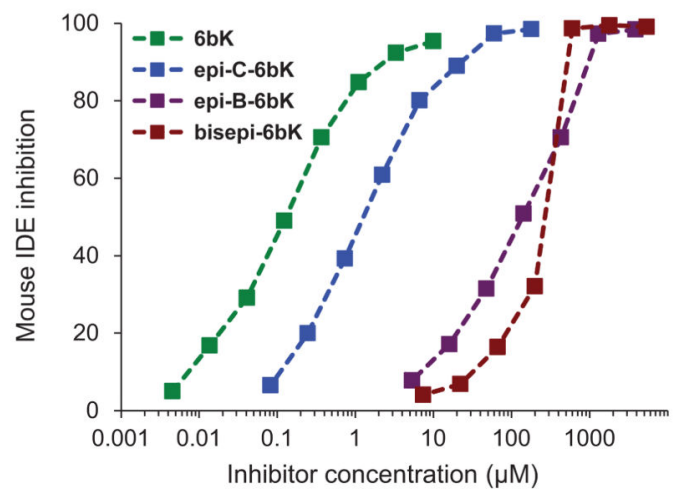

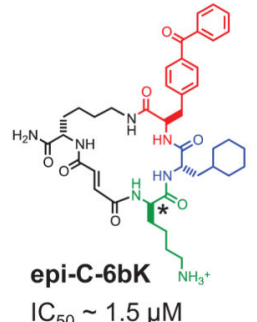

$\mathrm{IC}_{50} \sim 1.5 \mu \mathrm{M}$

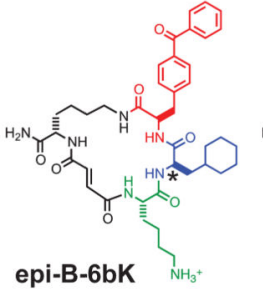

$\mathrm{IC}_{50}=100 \mu \mathrm{M}$

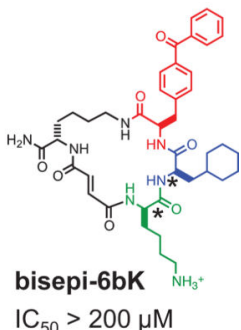

b Lean mice IPGTT, dose 2.25 mg/animal

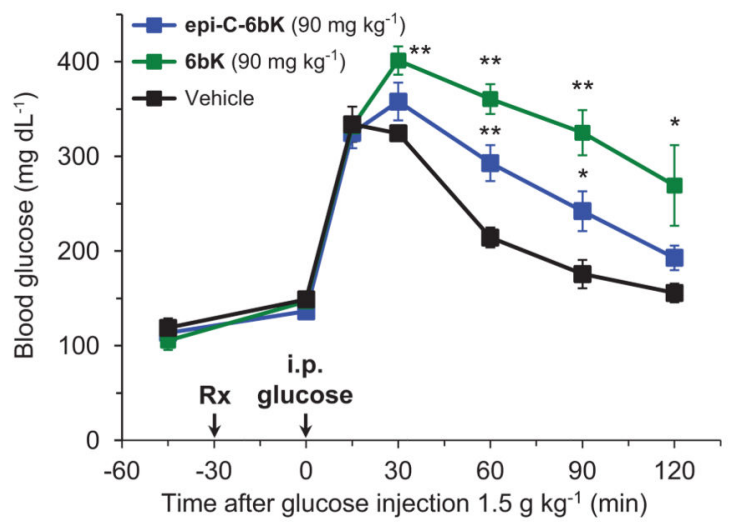

C Lean mice IPGTT, doses 1 and 2 mg/animal

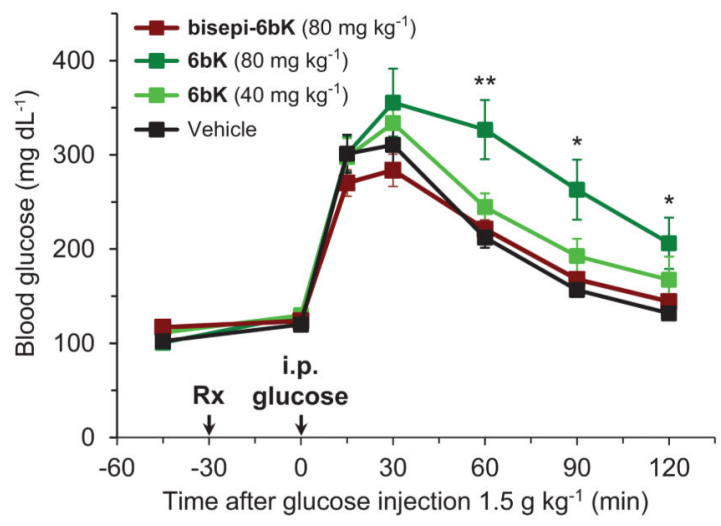

d DIO mice IPGTT, dose 1.5 mg/animal

e DIO mice IPGTT, dose 3.5 mg/animal

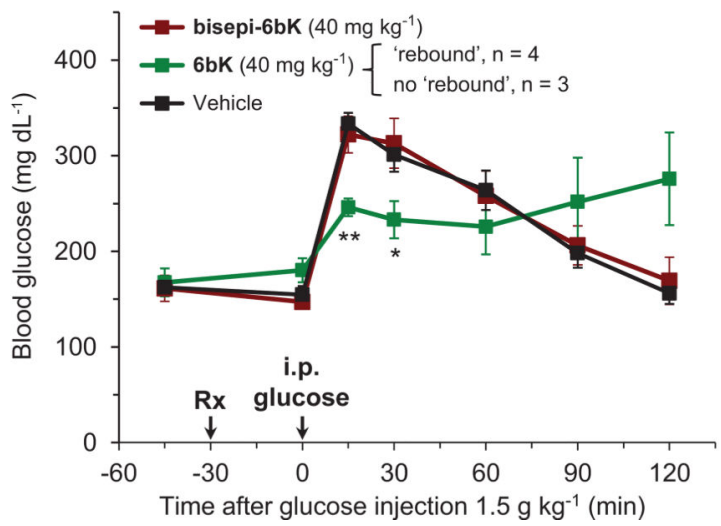

Extended Data Figure 7. Low-potency diastereomers of $6 \mathrm{bK}$ used to determine effective dose range and confirm on-target IDE inhibition effects during IPGTTs

a, Left, inhibition of mouse IDE activity by low potency diastereomers of $\mathbf{6 b K}$ (right). The stereocentres altered in each compound relative to those of $\mathbf{6 b K}$ are labelled with asterisks. b-e, In dose optimization experiments, the effects of $\mathbf{6 b K}$ (40 to $90 \mathrm{mg} \mathrm{kg}^{-1}, n=5$ and 4 , respectively) were compared with equal doses of either weakly active stereoisomer epiC-6bK ( $n=5$, panel b) or inactive stereoisomer bisepi-6bK $(n=5$, panel c) and vehicle controls $(n=5)$ in IPGTTs using lean and obese mice. $\mathbf{d}$, DIO mice treated with low doses 
of $\mathbf{6 b K}\left(40 \mathrm{mg} \mathrm{kg}^{-1}, n=7\right.$ ) responded to IPGTT in either of two ways: improved glucose tolerance throughout the experiment $(n=3)$ or a hyperglycaemic 'rebound' as described in the main text $(n=4)$, suggesting this dose is too low to achieve a consistent 'rebound' phenotype (note the large error bars). e, DIO mice treated with high doses of $\mathbf{6 b K}$ (3.5 mg per animal, $\left.90 \mathrm{mg} \mathrm{kg}^{-1}, n=5\right)$ respond similarly to Fig. 2e (2 mg per animal, $\left.60 \mathrm{mg} \mathrm{kg}^{-1}\right)$, but the weak activity observed for bisepi-6bK $\left(\mathrm{IC}_{50}>200 \mu \mathrm{M}\right)$ using a matching dose (90 $\left.\mathrm{mg} \mathrm{kg}^{-1}, n=5\right)$ compared to vehicle alone $(n=5)$ suggests that $60 \mathrm{mg} \mathrm{kg}^{-1}(2 \mathrm{mg}$ per animal) is the appropriate dose for DIO mice experiments. All data points and error bars represent mean \pm s.e.m. Statistics were performed using a two-tail Student's $t$-test, and significance levels shown in the figures are $* P<0.05$ versus vehicle control group; $* * P<$ 0.01 versus vehicle control group. Data shown in $\mathbf{b}-\mathbf{e}$ are representative of two or more independent studies.

a Oral glucose, DIO mice co-administered 6bK and DPP4 inhibitor sitagliptin

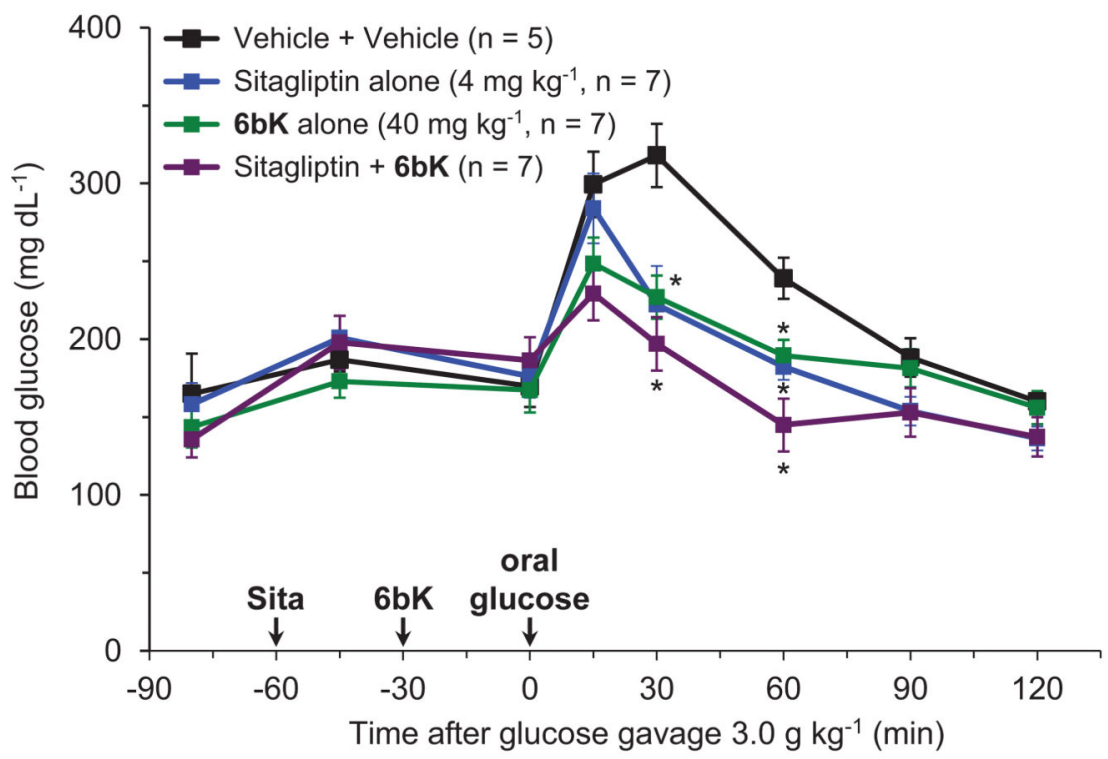

b

OGTT blood glucose profile areas

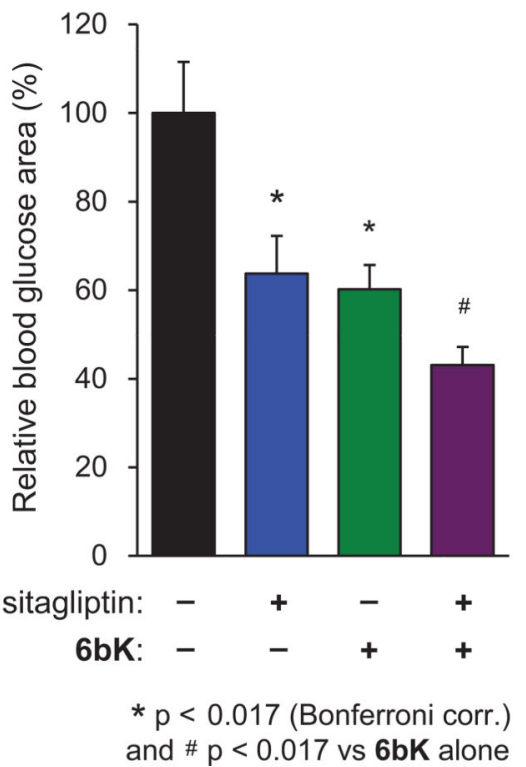

Extended Data Figure 8. Effects of co-administration of 6bK and dipeptidyl peptidase 4 (DPP4) inhibitor sitagliptin followed by oral glucose challenge

a, DIO mice were first treated with either oral gavage of sitagliptin $\left(4 \mathrm{mg} \mathrm{kg}^{-1}, 5 \mathrm{ml} \mathrm{kg}^{-1}\right.$ in sterile saline, $n=14$ ) or saline alone $(n=12)$. After $30 \mathrm{~min}$, each group of mice were treated either with a low dose of $\mathbf{6 b K}\left(40 \mathrm{mg} \mathrm{kg}^{-1}, n=7\right)$ or vehicle alone $(n=5)$, and after an additional 30 min all mice were given a bolus of glucose by gavage $\left(3.0 \mathrm{~g} \mathrm{~kg}^{-1}, 10 \mathrm{ml} \mathrm{kg}{ }^{-1}\right)$. Mice treated with the combination of sitagliptin and $\mathbf{6 b K}$ displayed glucose levels lower than baseline $(t=0)$ after $60 \mathrm{~min}$. $\mathbf{b}$, Blood glucose profile areas of sitagliptin and $\mathbf{6 b k}$ were similarly reduced by 60-64\% compared to vehicle alone, and further $15 \%$ lower when sitagliptin and $\mathbf{6 b K}$ were co-administered. Symbol and bar colour-coding: black, vehicle alone; blue, sitagliptin alone; green, $6 \mathbf{b K}$ alone; purple, sitagliptin $+\mathbf{6 b K}$. All data points and error bars represent mean \pm s.e.m. Statistics were performed using a one-tail Student's $t$ test. Significance levels shown in the figures are: ${ }^{*} P<0.017$ (Bonferroni correction) versus 
vehicle control group, ${ }^{\#} P<0.017$ versus the $\mathbf{6 b K}$ cohort. See Supplementary Methods for a description of the AUC calculation. The data shown are from a study performed once.

a

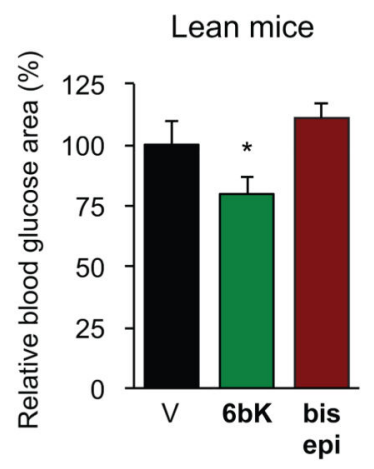

b

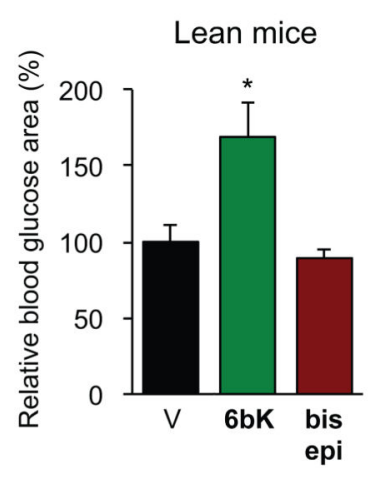

C

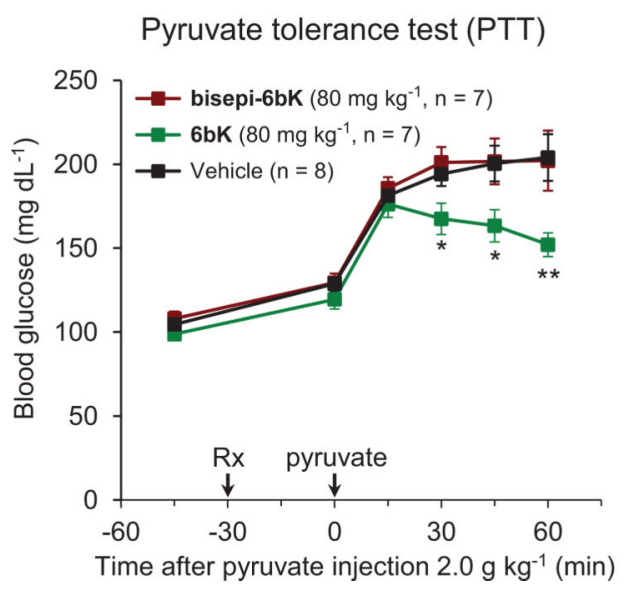

OGTT blood glucose profile areas

DIO mice

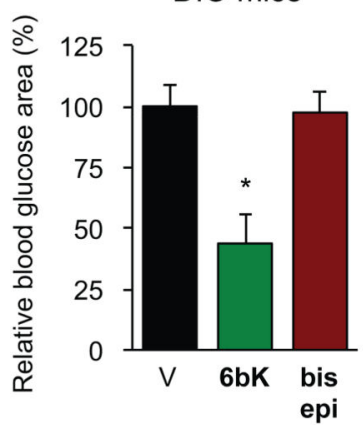

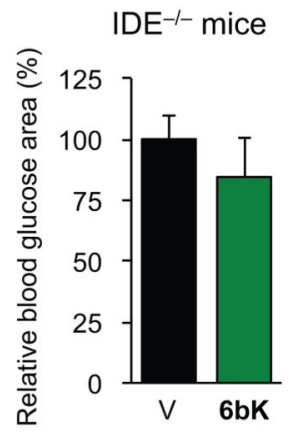

IPGTT blood glucose profile areas

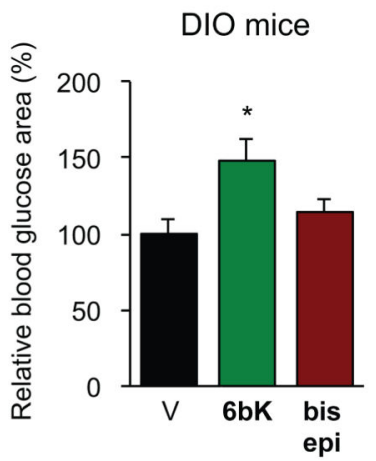

d

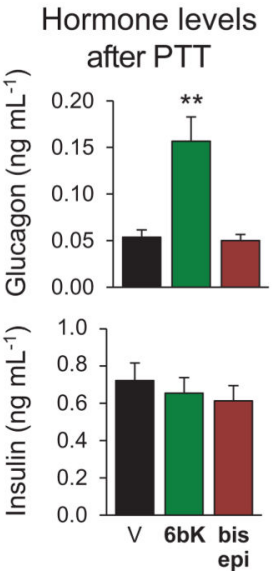

$\mathrm{IDE}^{-/-}$mice

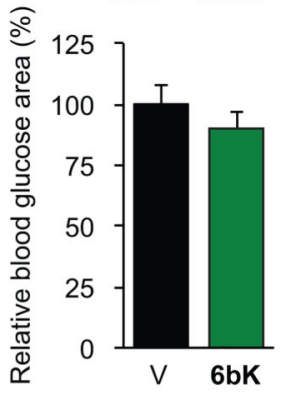

e

Liver gluconeogenesis markers $60 \mathrm{~min}$ post-PTT

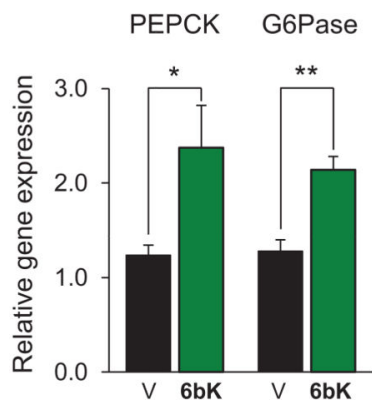

Extended Data Figure 9. Glucose tolerance test $\mathrm{AUC}$ (area under the curve) calculations, and pyruvate tolerance test for gluconeogenesis during IDE inhibition

a, AUC calculations for Fig. 2 data show that during OGTT, lean and DIO mice treated with 6bK display improved glucose tolerance, compared to vehicle controls and inactive bisepi-6bK. b, In contrast, during IPGTT both lean and DIO mice treated with $6 \mathbf{b K}$ display impaired glucose tolerance compared to vehicle or bisepi-6bK controls. The AUCs for $\mathbf{6 b K}$ 
versus vehicle treatments using $I d e^{-/-}$mice are similar for both OGTT and IPGTT. c, Wildtype mice fasted overnight were injected i.p. with pyruvate $\left(2.0 \mathrm{~g} \mathrm{~kg}^{-1}\right) 30 \mathrm{~min}$ after treatment with $\mathbf{6 b K}$, inactive analogue bisepi-6bK, or vehicle alone. d, Plasma hormone measurements $60 \mathrm{~min}$ post-PTT reveal elevated glucagon (top) but similar insulin (bottom) levels for the $\mathbf{6 b K}$-treated cohort relative to bisepi-6bK or vehicle controls. e, RT-PCR analysis of liver samples 60-min post-PTT revealed elevated gluconeogenesis transcriptional markers for the $\mathbf{6 b K}$-treated group relative to vehicle controls. All data points and error bars represent mean \pm s.e.m. Statistics were performed using a two-tail Student's $t$-test, and significance levels shown in the figures are $* P<0.05$ versus vehicle control group; $* * P<$ 0.01 versus vehicle control group. See Supplementary Methods for a description of the AUC calculation. Data shown not involving knockout mice are representative of two or more independent studies; studies on knockout mice and PTT measurements were performed once.
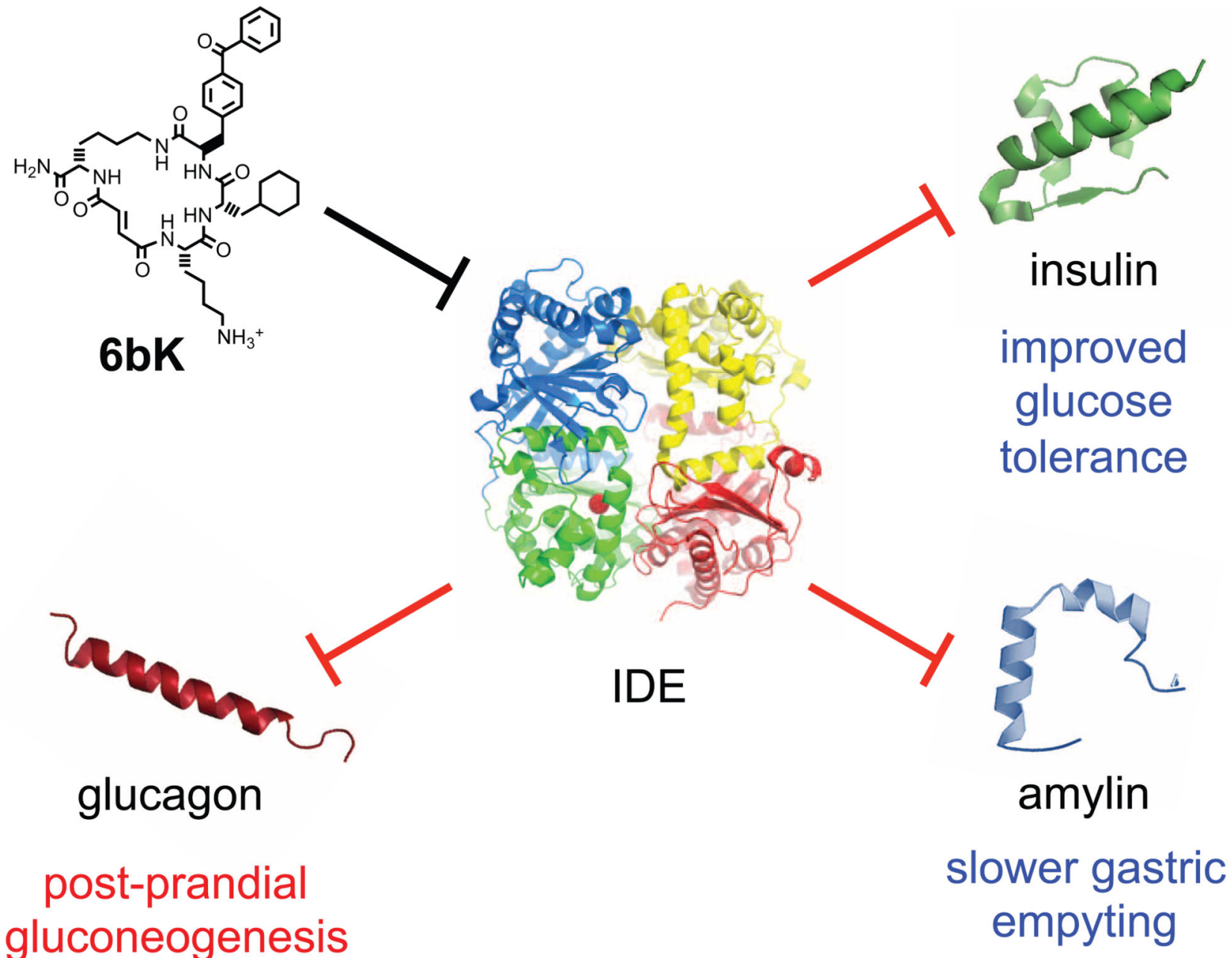

\section{post-prandial gluconeogenesis}

Extended Data Figure 10. Model for the expanded roles of IDE in glucose homeostasis and gastric emptying based on the results of this study 
IDE inhibition increases the abundance and signalling of three key pancreatic peptidic hormones —insulin, amylin and glucagon — with the corresponding physiological effects shown in blue, blue and red, respectively.

\section{Acknowledgments}

This research was supported by NIH/NIGMS (R01 GM065865 (D.R.L.), R00 GM080097 (M.A.S.), R01 GM81539 (W.-J.T.), T32 GM008444 (Z.H.F.), F30 CA174152 (Z.H.F.), DP2 OD002374 (A.S.)), Howard Hughes Medical Institute (D.R.L.), Diabetes and Cancer Centers of Albert Einstein College of Medicine (M.J.C.), American Diabetes Association no. 7-11-CD-06 (M.A.L.), Burroughs Wellcome Fund CABS (A.S.), and the Searle Scholars Program(A.S.). The Fonds de Recherche en Santé du Québec (FRSQ) and the Alfred Bader Fund supported J.P.M. We thank C. Russ and H. Spurling (Broad Institute) and C. Daly (FAS Center for Systems Biology) for DNA sequencing assistance. We are grateful to S. Johnston and C. Mosher (Broad Institute) for $\mathbf{6} \mathbf{b K}$ stability measurements. W. Nolte provided mouse IDE, L. McCord purified CF-IDE and Y.-G. Kim performed CGRP cleavage assays. We are grateful to A. Badran, E. Homan, A. M. Lone and M. Leidl (Harvard University) for experimental assistance. We thank B. Kahn and N. Gray for discussions.

\section{References}

1. Duckworth WC, Bennett RG, Hamel FG. Insulin degradation: progress and potential. Endocr. Rev. 1998; 19:608-624. [PubMed: 9793760]

2. Mirsky IA, Broh-Kahn RH. The inactivation of insulin by tissue extracts the distribution and properties of insulin inactivating extracts. Arch. Biochem. 1949; 20:1-9. [PubMed: 18104389]

3. Sladek R, et al. A genome-wide association study identifies novel risk loci for type 2 diabetes. Nature. 2007; 445:881-885. [PubMed: 17293876]

4. Zeggini E, et al. Replication of genome-wide association signals in UK samples reveals risk loci for type 2 diabetes. Science. 2007; 316:1336-1341. [PubMed: 17463249]

5. Farris W, et al. Insulin-degrading enzyme regulates the levels of insulin, amyloid beta-protein, and the beta-amyloid precursor protein intracellular domain in vivo. Proc. Natl Acad. Sci. USA. 2003; 100:4162-4167. [PubMed: 12634421]

6. Abdul-Hay SO, et al. Deletion of insulin-degrading enzyme elicits antipodal, age-dependent effects on glucose and insulin tolerance. PLoS ONE. 2011; 6:e20818. [PubMed: 21695259]

7. Gartner ZJ, et al. DNA-templated organic synthesis and selection of a library of macrocycles. Science. 2004; 305:1601-1605. [PubMed: 15319493]

8. Tse BN, Snyder TM, Shen Y, Liu DR. Translation of DNA into a library of 13,000 synthetic smallmolecule macrocycles suitable for in vitro selection. J. Am. Chem. Soc. 2008; 130:15611-15626. [PubMed: 18956864]

9. Kim YG, Lone AM, Nolte WM, Saghatelian A. Peptidomics approach to elucidate the proteolytic regulation of bioactive peptides. Proc. Natl Acad. Sci. USA. 2012; 109:8523-8527. [PubMed: 22586115]

10. Leissring MA, et al. Designed inhibitors of insulin-degrading enzymeregulate the catabolism and activity of insulin. PLoS ONE. 2010; 5:e10504. [PubMed: 20498699]

11. Malito E, et al. Molecular bases for the recognition of short peptide substrates and cysteinedirected modifications of human insulin-degrading enzyme. Biochemistry. 2008; 47:12822-12834. [PubMed: 18986166]

12. Malito E, Hulse RE, Tang WJ. Amyloid beta-degrading cryptidases: insulin degrading enzyme, presequence peptidase, and neprilysin. Cell. Mol. Life Sci. 2008; 65:2574-2585. [PubMed: 18470479]

13. Shen Y, Joachimiak A, Rosner MR, Tang WJ. Structures of human insulin-degrading enzyme reveal a new substrate recognition mechanism. Nature. 2006; 443:870-874. [PubMed: 17051221]

14. Manolopoulou M, Guo Q, Malito E, Schilling AB, Tang WJ. Molecular basis of catalytic chamberassisted unfolding and cleavage of human insulin by human insulin-degrading enzyme. J. Biol. Chem. 2009; 284:14177-14188. [PubMed: 19321446]

15. Stella VJ, He Q. Cyclodextrins. Toxicol. Pathol. 2008; 36:30-42. [PubMed: 18337219] 
16. Andrikopoulos S, Blair AR, Deluca N, Fam BC, Proietto J. Evaluating the glucose tolerance test in mice. Am. J. Physiol. Endocrinol. Metab. 2008; 295:E1323-E1332. [PubMed: 18812462]

17. Ahrén B, Winzell MS, Pacini G. The augmenting effect on insulin secretion by oral versus intravenous glucose is exaggerated by high-fat diet in mice. J. Endocrinol. 2008; 197:181-187. [PubMed: 18372244]

18. Winzell MS, Ahren B. The high-fat diet-fed mouse: a model for studying mechanisms and treatment of impaired glucose tolerance and type 2 diabetes. Diabetes. 2004; 53(Suppl 3):S215S219. [PubMed: 15561913]

19. Drucker DJ. The biology of incretin hormones. Cell Metab. 2006; 3:153-165. [PubMed: 16517403]

20. Riddle MC, Drucker DJ. Emerging therapies mimicking the effects of amylin and glucagon-like peptide 1. Diabetes Care. 2006; 29:435-449. [PubMed: 16443905]

21. Mooradian AD, Thurman JE. Drug therapy of postprandial hyperglycaemia. Drugs. 1999; 57:19_ 29. [PubMed: 9951949]

22. Duckworth WC, Kitabchi AE. Insulin and glucagon degradation by the same enzyme. Diabetes. 1974; 23:536-543. [PubMed: 4834293]

23. Bennett RG, Duckworth WC, Hamel FG. Degradation of amylin by insulin-degrading enzyme. J. Biol. Chem. 2000; 275:36621-36625. [PubMed: 10973971]

24. Young A. Effects on plasma glucose and lactate. Adv. Pharmacol. 2005; 52:193-208. [PubMed: 16492547]

25. Gedulin BR, Jodka CM, Herrmann K, Young AA. Role of endogenous amylin in glucagon secretion and gastric emptying in rats demonstrated with the selective antagonist, AC187. Regul. Pept. 2006; 137:121-127. [PubMed: 16914214]

26. Gelling RW, et al. Lower blood glucose, hyperglucagonemia, and pancreatic alpha cell hyperplasia in glucagon receptor knockout mice. Proc. Natl Acad. Sci. USA. 2003; 100:1438-1443. [PubMed: 12552113]

27. Unger RH, Cherrington AD. Glucagonocentric restructuring of diabetes: a pathophysiologic and therapeutic makeover. J. Clin. Invest. 2012; 122:4-12. [PubMed: 22214853]

28. Sadry SA, Drucker DJ. Emerging combinatorial hormone therapies for the treatment of obesity and T2DM. Nature Rev. Endocrinol. 2013; 9:425-433. [PubMed: 23478327] 
a and stereochemistry required

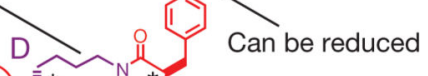

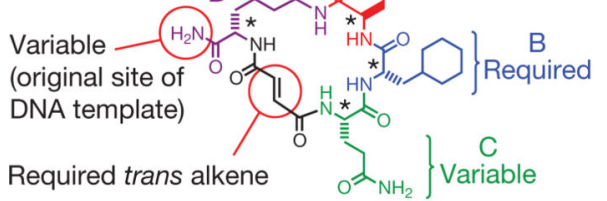

Required trans alken

$$
\begin{gathered}
\quad 6 \mathbf{b} \\
\mathrm{IC}_{50}=60 \mathrm{nM}
\end{gathered}
$$

b

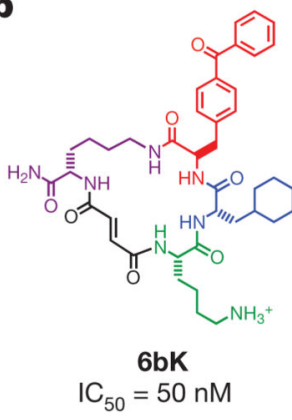

c

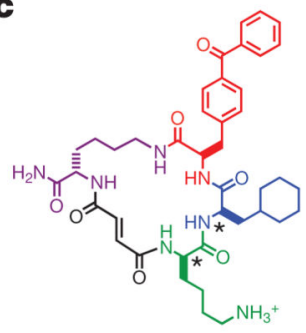

bisepi-6bK d

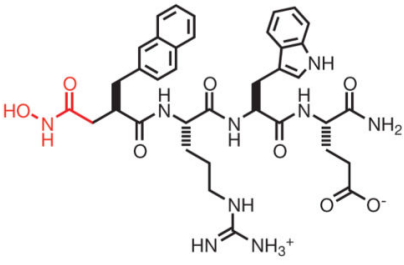

li1 e

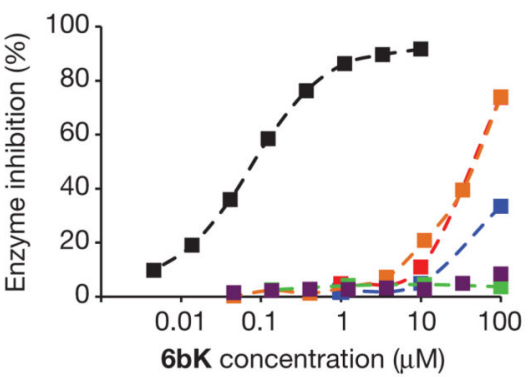

$$
\begin{aligned}
& \rightarrow \mathrm{IDE} \rightarrow \mathrm{NLN} \rightarrow \mathrm{THOP} \\
& \rightarrow \mathrm{NEP} \rightarrow \mathrm{MMP} 1 \rightarrow \mathrm{ACE}
\end{aligned}
$$

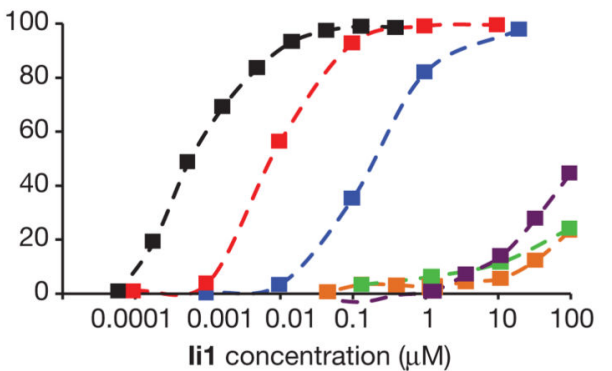

$\mathbf{f}$

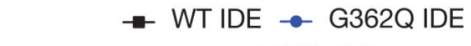
^ A479L IDE

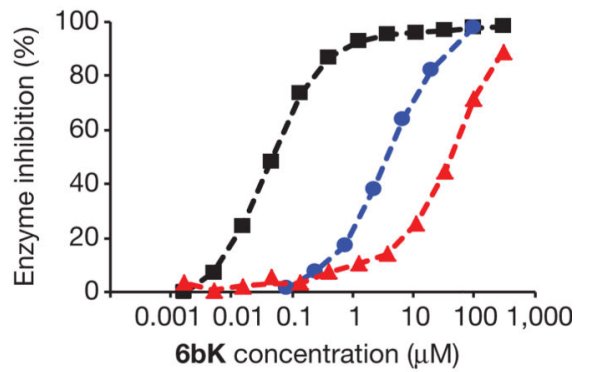

\section{g}

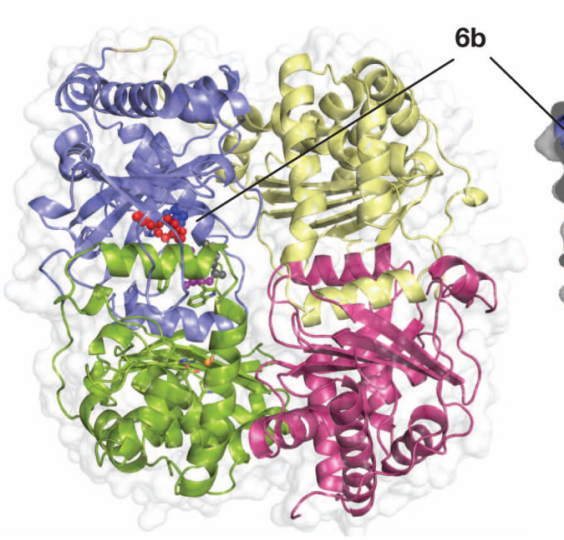

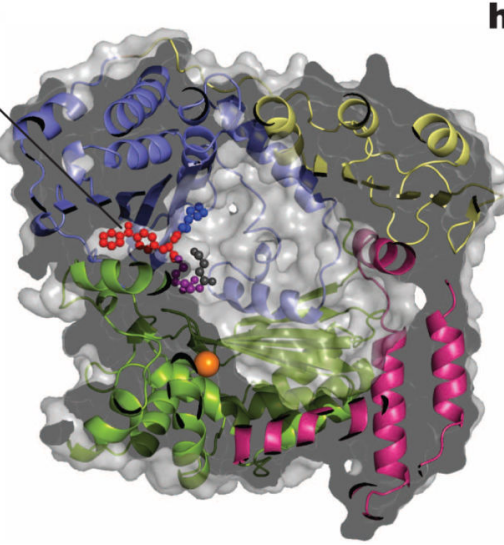

h Gly 36

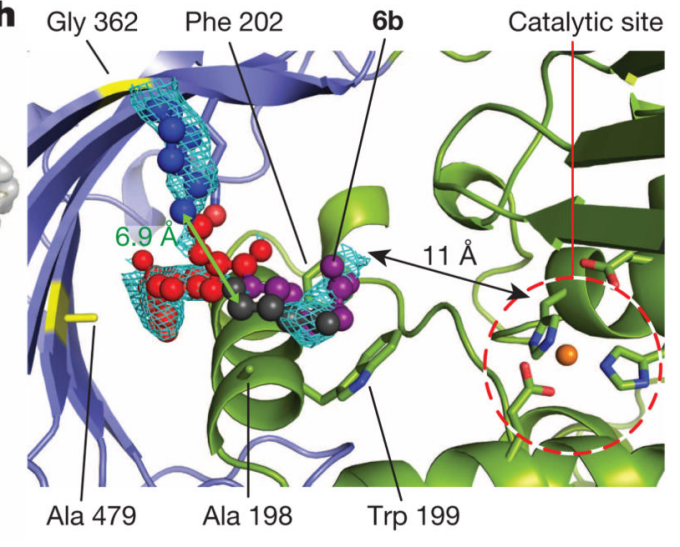

Figure 1. Potent and highly selective macrocyclic IDE inhibitors from the in vitro selection of a DNA-templated macrocycle library

$\mathbf{a}$, Structure of $\mathbf{6 b}$ and summary of the requirements for IDE inhibition revealed by assaying 6b analogues (Extended Data Fig. 1). b, Physiologically active IDE inhibitor 6bK. c, Inactive diastereomer bisepi-6bK. d, Previously reported substrate-mimetic hydroxamic acid $\mathrm{Ii1}^{10}$. e, Selectivity analysis of macrocycle $\mathbf{6 b K}$ reveals $>1,000$-fold selectivity for IDE $\left(\mathrm{IC}_{50}=50 \mathrm{nM}\right)$ over all other metalloproteases tested. In contrast, inhibitor Ii1 $^{10}$ inhibits IDE $\left(\mathrm{IC}_{50}=0.6 \mathrm{nM}\right)$, thimet oligopeptidase (THOP, $\left.\mathrm{IC}_{50}=6 \mathrm{nM}\right)$ and neurolysin $(\mathrm{NLN}$, $\mathrm{IC}_{50}=185 \mathrm{nM}$ ), but not NEP (neprilysin), MMP1 (matrix metalloproteinase, 1) or ACE (angiotensin-converting enzyme). f, Activity assays for wild-type or mutant human IDE variants in the presence of $\mathbf{6 b K}$. $\mathbf{g}$, X-ray co-crystal structure of IDE bound to macrocyclic inhibitor $\mathbf{6 b}$ (2.7 ̊̊ resolution, PDB 4LTE). h, Electron density map (composite omit map contoured at $1 \sigma$ ) showing the relative position of macrocycle $\mathbf{6 b}$ bound $11 \AA$ from the 
catalytic zinc atom. The glutamine residue and four atoms of the macrocycle backbone were unresolved. See also Extended Data Figs 2-4. 
a

Oral glucose, lean mice

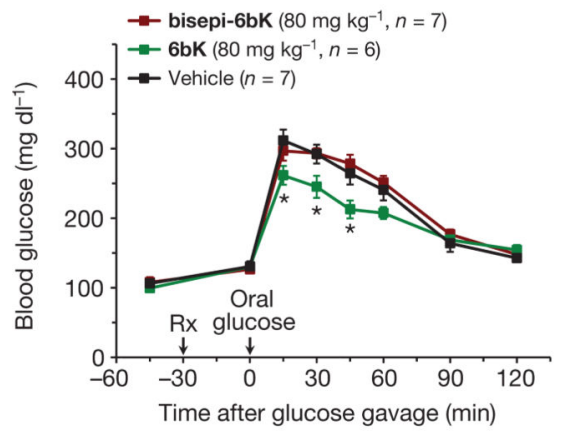

d

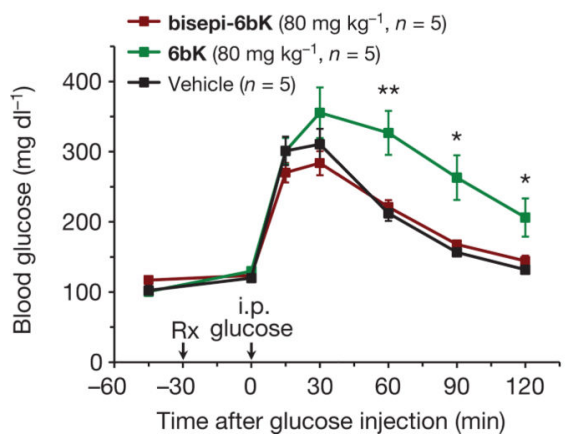

b

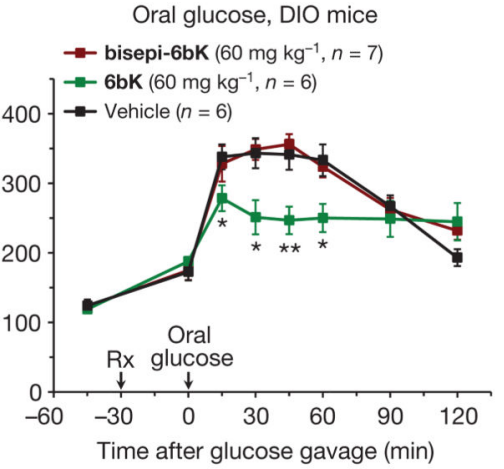

e

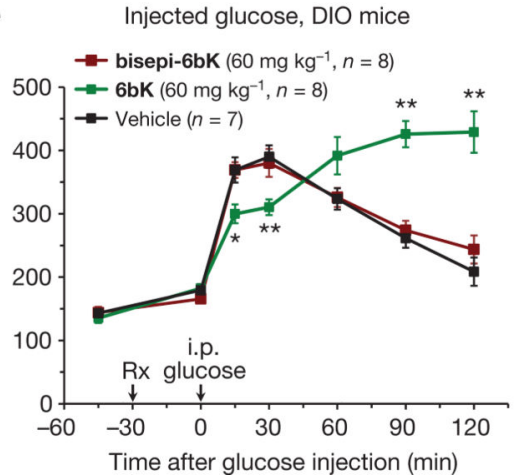

c

Oral glucose, $/ d e^{-/-}$mice

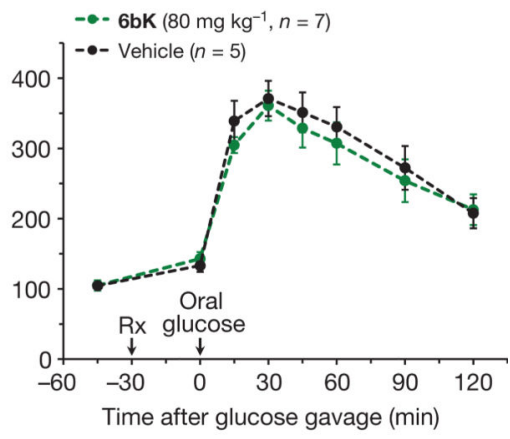

$\mathbf{f}$

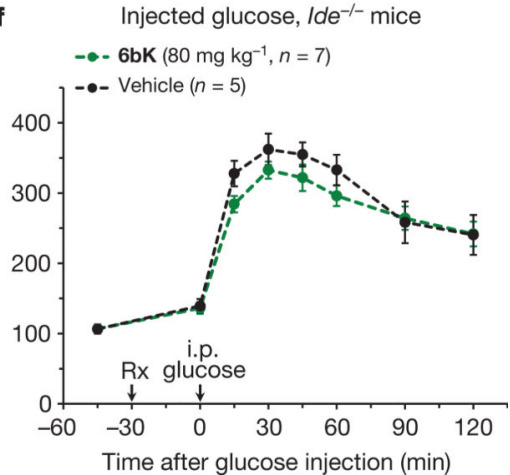

Figure 2. Physiological consequences of acute IDE inhibition by $6 \mathrm{bK}$ on glucose tolerance in lean, DIO and $\mathrm{Ide}^{-/-}$mice

a, b, Oral glucose tolerance during acute IDE inhibition. a, Male C57BL/6J lean (25 g) mice were treated (at time Rx) with a single i.p. injection of IDE inhibitor $6 \mathbf{b K}$, inactive control bisepi-6bK, or vehicle alone, $30 \mathrm{~min}$ before glucose gavage $\left(3.0 \mathrm{~g} \mathrm{~kg}^{-1}\right)$. b. DIO mice (35$45 \mathrm{~g}$ ) were treated with $\mathbf{6 b K}$, and inactive control bisepi-6bK or vehicle alone $30 \mathrm{~min}$ before glucose gavage $\left(3.0 \mathrm{~g} \mathrm{~kg}^{-1}\right)$. c, Mice lacking the target $\left(I d e^{-/-}\right)$treated with $\mathbf{6 b K}$ followed by oral glucose $\left(3.0 \mathrm{~g} \mathrm{~kg}^{-1}\right)$ produce a response comparable to that of vehicletreated $I d e^{-/-}$mice. d, e, Glucose tolerance phenotypes after i.p. injection of glucose $(1.5 \mathrm{~g}$ $\mathrm{kg}^{-1}$ ) in, respectively, lean (d) and DIO (e) male mice treated with $\mathbf{6 b K}$, inactive bisepi-6bK, or vehicle alone. f, Mice lacking IDE treated with $\mathbf{6 b K}$ followed by IPGTT (1.5 $\mathrm{g} \mathrm{kg}^{-1}$ ) produce a response comparable to that of vehicle-treated $I d e^{-l-}$ mice. Area under the curve (AUC) calculations are shown in Extended Data Fig. 9. Data: mean \pm s.e.m.; ${ }^{*} P<$ $0.05,{ }^{*} P<0.01$ in two-tail Student's $t$-test. Data shown in $\mathbf{a , ~} \mathbf{b}, \mathbf{d}$ and $\mathbf{e}$ are representative of two or more independent studies. Control studies using knockout mice were performed once. 


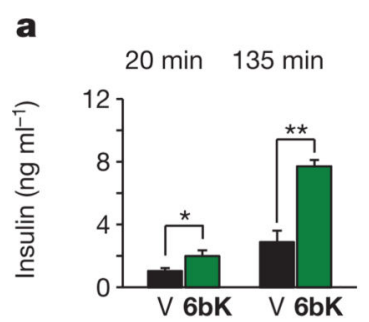

b

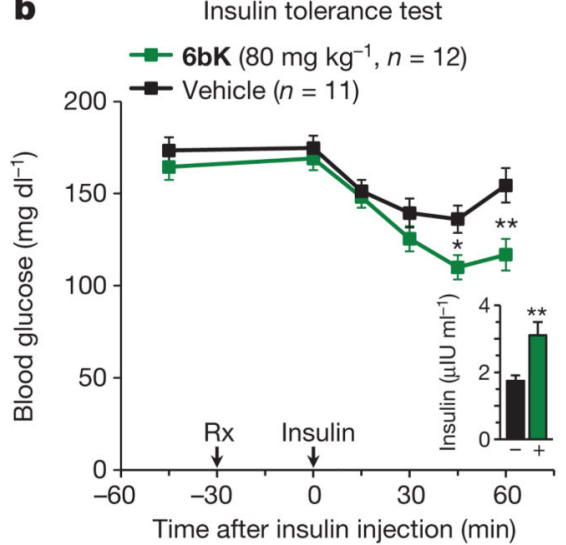

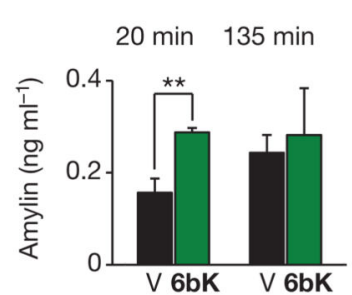

c

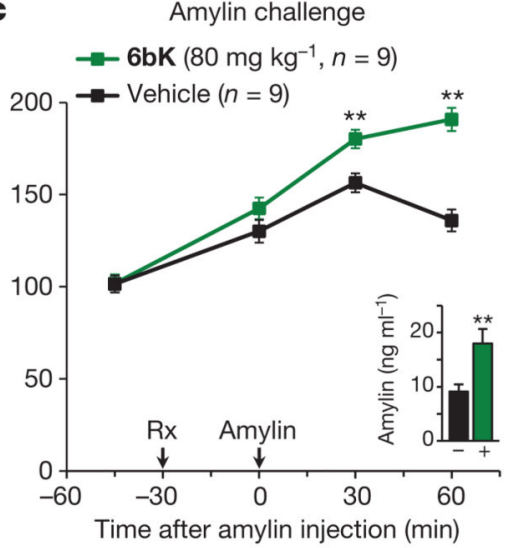

$135 \mathrm{~min}$

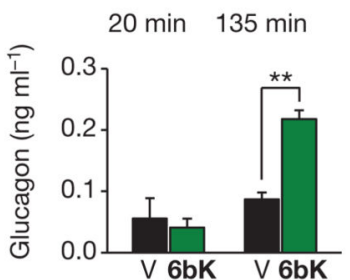

PEPCK G6Pase

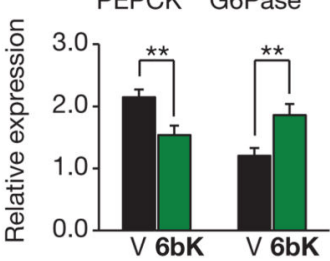

d

d Glucagon challenge

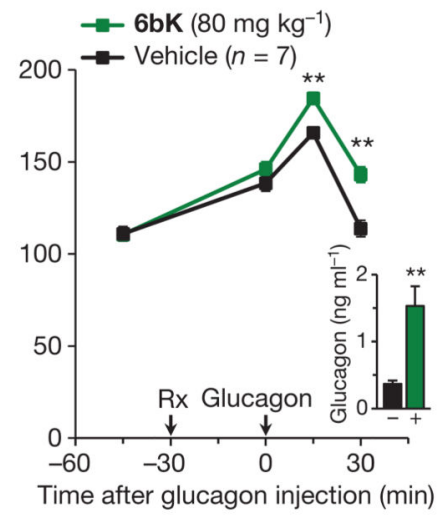

e

Amylin-induced gastric rentention

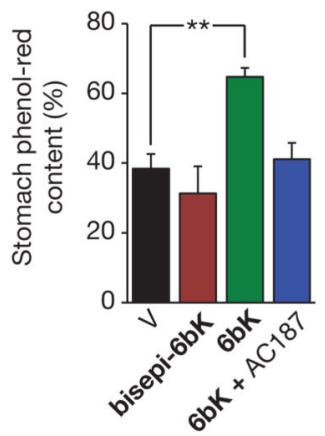

f

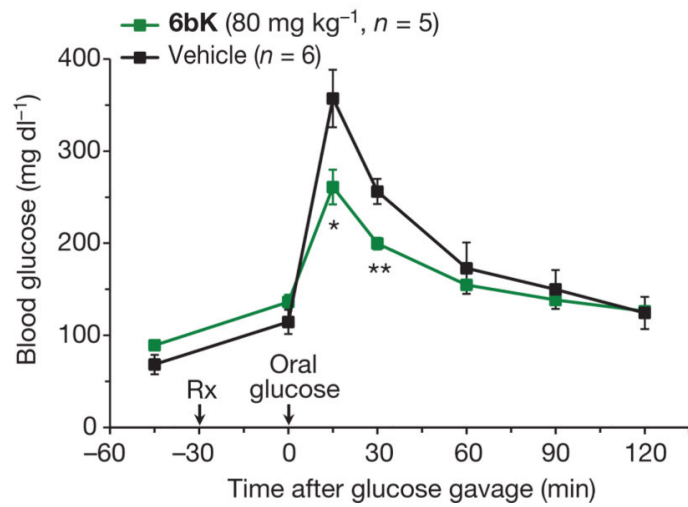

9

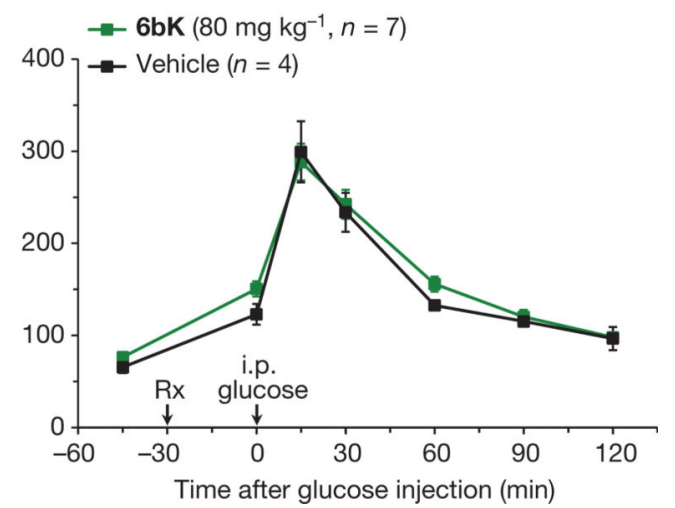

Figure 3. Acute IDE inhibition affects the abundance of multiple hormone substrates and their corresponding effects on blood glucose levels

a, Plasma hormone measurements at $20 \mathrm{~min}$ and $135 \mathrm{~min}$ after i.p.-injected glucose tolerance tests (IPGTTs) on DIO mice (Fig. 2e) and RT-PCR analysis of DIO liver samples collected at 135 min after IPGTT. RT-PCR reveals 50\% higher glucose-6-phosphatease (G6Pase) and 30\% lower phosphoenolpyruvate carboxykinase (PEPCK) transcript levels for the 6bK-treated cohort (6bK; $n=7)$ versus vehicle-only controls (V; $n=7)$. b-d, Blood glucose responses and injected hormone abundances in lean mice $30 \mathrm{~min}$ after treatment with $\mathbf{6 b K}$ or vehicle alone. $\mathbf{b}$, Insulin $\left(0.25 \mathrm{U} \mathrm{kg}^{-1}\right.$, subcutaneous $)$ after 5 -h fast. c, Amylin (250 $\mu \mathrm{g} \mathrm{kg}^{-1}$, subcutaneous) after overnight fast. d, Glucagon (100 $\mathrm{g} \mathrm{kg}^{-1}$, subcutaneous) after overnight fast. Trunk blood was collected at the last time-points for plasma hormone measurements (insets; IU, international units). e, Acute IDE inhibition slows gastric emptying through amylin signalling. Fasted WT mice were given oral glucose supplemented with $0.1 \mathrm{mg} \mathrm{ml}^{-1}$ phenol red $30 \mathrm{~min}$ after treatment with $\mathbf{6 b K}$ alone $(n=6), \mathbf{6 b K}$ co- 
administered with the amylin receptor antagonist ${ }^{25} \mathrm{AC} 187$ (3 $\mathrm{mg} \mathrm{kg}^{-1}$ i.p., $\left.n=6\right)$, vehicle alone $(\mathrm{V} ; n=6)$ or inactive bisepi-6bK $(n=4) . \mathbf{f}, \mathbf{g}$, G-protein-coupled glucagon receptor knockout mice $\left(\mathrm{Gcgr}^{--}\right)$treated with IDE inhibitor $\mathbf{6} \mathbf{b K}$ display altered glucose tolerance relative to vehicle-treated mice if challenged with oral glucose $\left(3.0 \mathrm{~g} \mathrm{~kg}^{-1} ; \mathbf{f}\right)$ but not i.p. injected glucose $\left(1.5 \mathrm{~g} \mathrm{~kg}^{-1} ; \mathbf{g}\right)$. Data: mean \pm s.e.m.; $* P<0.05$, $* * P<0.01$ in two-tail Student's $t$-test. Data shown in a-e are representative of two or more independent studies. Studies using $\mathrm{Gcgr}^{-/-}$knockout mice were performed once. 